\title{
Fully Resolved Modelling and Simulation of Micromixing in Confined Impinging Jets
}

DOI:

10.1016/j.ces.2019.115299

\section{Document Version}

Accepted author manuscript

Link to publication record in Manchester Research Explorer

\section{Citation for published version (APA):}

Brito, M. S. C. A., Dias, M. M., Santos, R. J., Lopes, J. C. B., \& Da Fonte, C. P. (2019). Fully Resolved Modelling and Simulation of Micromixing in Confined Impinging Jets. Chemical Engineering Science, 115299.

https://doi.org/10.1016/j.ces.2019.115299

\section{Published in:}

Chemical Engineering Science

\section{Citing this paper}

Please note that where the full-text provided on Manchester Research Explorer is the Author Accepted Manuscript or Proof version this may differ from the final Published version. If citing, it is advised that you check and use the publisher's definitive version.

\section{General rights}

Copyright and moral rights for the publications made accessible in the Research Explorer are retained by the authors and/or other copyright owners and it is a condition of accessing publications that users recognise and abide by the legal requirements associated with these rights.

\section{Takedown policy}

If you believe that this document breaches copyright please refer to the University of Manchester's Takedown Procedures [http://man.ac.uk/04Y6Bo] or contact uml.scholarlycommunications@manchester.ac.uk providing relevant details, so we can investigate your claim.

\section{OPEN ACCESS}


1 Fully Resolved Modelling and Simulation of Micromixing in Confined

2 Impinging Jets

\author{
M.S.C.A. Brito ${ }^{1}$, M.M. Dias ${ }^{1}$, R.J. Santos ${ }^{1}$, J.C.B. Lopes ${ }^{1}$, C.P. Fonte ${ }^{2 *}$
}

${ }^{1}$ Laboratory of Separation and Reaction Engineering - Laboratory of Catalysis and Materials (LSRE-LCM, Faculdade de Engenharia, Universidade do Porto, Rua Dr Roberto Frias, 4200-465 Porto, Portugal

${ }^{2}$ School of Chemical Engineering and Analytical Science, The University of Manchester, Oxford Road, Manchester M13 9PL, U.K.

\begin{abstract}
Confined Impinging Jets (CIJs) are fast mixing meso sized devices for fast reaction applications, where two opposed jets contact the reactants that are mixed by chaotic flow patterns in very short times. Fully resolved CFD chemical reaction in CIJs is out of reach for engineering practice since on the order of $10^{11}$ computational cells would be required. This paper presents a theoretical methodology to describe micromixing in CIJs using a lamellar model that considers the dynamics of striation thinning and diffusion at the interface of the mixing fluids. A lamellar micromixing (LM) model based on mixing evolution functions was applied to simulate chemical reactions. The evolution of mixing scales in CIJs was also studied from fully-resolved CFD simulations that validate the mixing scales predicted from theoretical models. This LM model completely describes the experimental results, and it is thus directly applicable to the design of CIJs technology for chemical processes.
\end{abstract}

\title{
Keywords
}

Mixing; Chemical reactor; Micromixing test reactions; Confined Impinging Jets; Lamellar Model; Computational Fluid Dynamics.

*claudio.fonte@manchester.ac.uk 


\section{Introduction}

Simulation of complex fast reactions in a reactor can only be done accurately when the micromixing scales are fully resolved. This spatial resolution is not feasible even for simulation of micro/milli sized reactors in chaotic flow regimes. Considering typical values for diffusivity of liquids, $D_{i}=10^{-9} \mathrm{~m}^{2} / \mathrm{s}$, in micro/milli-reactors with micromixing times around $t_{\text {micromixing }}=0.1 \mathrm{~s}$, the length scale of micromixing is within the order of $\Delta x=10$ to $1 \mu \mathrm{m}$. The Computational Fluid Dynamics (CFD) simulation of such a reactor with volumes of $50 \mathrm{~cm}^{3}$ would need more than $10^{11}$ cells, a value that is orders of magnitude larger than usual reasonable values for CFD simulations. In the present paper this major problem is addressed and solved, by decoupling the flow dynamics and the micromixing scales to enable the fully resolved simulation of a complex chemical reaction in Confining Impinging Jets (CIJ) reactors.

CIJ reactors have been used for fast mixing of viscous fluids in the plastics industry. One of the main applications for this technology is the processing of polyurethanes in Reaction Injection Moulding (RIM) that was patented in 1970 by Krauss-Maffei (Keuerleber and Pahl, 1970) and the most recent industrial developments in this processing technology were reviewed by Volpato and Fiorentini (2012) from the Cannon Group. RIM was simultaneously studied in late 70s early 80s at MIT (Malguarnera and Suh, 1977; Tucker and Suh, 1980) and University of Minnesota (Ritcher and Macosko, 1978; Lee et al., 1980). In these studies, the CIJs consisted on a cylindrical chamber having a diameter around $10 \mathrm{~mm}$ and height $50 \mathrm{~mm}$, with a single outlet and two opposed inlets placed at half diameter from the closed top (see the sketch of the CIJs in Figure 1). The Reynolds number in RIM is an important operational parameter and defined (Malguarnera and Suh (1977) at the inlet injectors as

$$
\operatorname{Re}=\frac{\rho v_{\text {inj }} d}{\mu}
$$

where $v_{\text {inj }}$ is the average velocity at the mixing chamber injectors, $d$ is the diameter of the injectors, $\rho$ and $\mu$ are the density and viscosity of the fluid respectively. Industrial practice for RIM processes stipulates that the operational Reynolds number for good mixing must be above 100 .

In typical RIM process, two organic monomer viscous streams are mixed in a CIJ mixer to form a reactive mixture having mixing scales usually smaller than $50 \mu \mathrm{m}$ (Ranz, 1986). This mixture of monomers is rapidly discharged into a mould where most of the polymerization occurs. The mixing time for CIJs in RIM is in the range of 10-100 ms. Effective mixing up to scales required for polymerization depends on the combined engulfment of the two monomer streams that only occurs when dynamic structures are formed in the CIJ mixing chamber (Lee et al., 1980).

Several authors have studied the mixing in CIJs from flow visualizations and reported two distinct flow regimes, segregated and chaotic flow regime (Lee et al., 1980; Tucker and Suh, 1980; Johnson et al., 1996; Johnson, 2000b; Santos et al., 2008; Santos et al., 2009; Fonte et al., 2015; Shi et al., 2015). Figure 1 shows PLIF images of mixing of a jet dyed with rhodamine, represented in dark colour, and a clear jet for both flow regimes. The experimental work regarding this visualization of mixing in CIJs was reported in Fonte et al. (2015) as well as more detailed results from PLIF experiments. Other authors obtained similar results with PLIF in CIJs (Li et al., 2015). Figure 1a shows the segregated flow regime at $\mathrm{Re}=103$, which is characterised by the fact that each side of the mixing chamber contains mainly one of the fluids. So, in each side there is a flow stream from the injector to the outlet delimited by the segregation plane that coincides with the mixing chamber axis and is normal to the inlets' axes. Figures $1 \mathrm{~b}$ and $1 \mathrm{c}$ show the PLIF images for chaotic flow regimes, for $\operatorname{Re}=111$ and $R e=505$, respectively. Figure $1 \mathrm{~b}$ shows that after the clear and dark coloured jets impinge at the mixing chamber axis, they spread and form vortices 
up and down the jets that engulf fluid from both jets. In Figure $1 \mathrm{~b}$ only one plane is visualized, but actually this spreading is radial and the vortices are formed around the jets (Unger et al., 1998; Zhao and Brodkey, 1998; Nakamura and Brodkey, 2000; Santos et al., 2009). At larger Reynolds numbers, see Figure 1c, vortices formed near the fluids' impingement region homogenizes both flow fluid streams and thus PLIF images become very homogeneous around the inlet jets.

Figure 1 shows that there is a critical Reynolds number that marks the transition between the two flow regimes. Experiments with flow visualization in cylindrical CIJ mixers (Tucker and Suh, 1980; Wood et al., 1991; Santos et al., 2009; Fonte et al., 2015) point to a critical Reynolds number between 110 and 150 .

Other operational conditions have been identified as playing a key role on mixing dynamics in CIJs. A major condition for mixing is the balancing of opposed jets inertia (Johnson, 2000b; Johnson, 2000a; Erkoç et al., 2007; Fonte et al., 2015; Fonte et al., 2016; Gomes et al., 2016). Furthermore, the inertia of the jets plays also a key role on mixing dynamics; this was analysed in terms of Froude number by Santos et al. (2002) and Santos et al. (2010) that showed, for fluids in water viscosity range, that the dynamics of mixing is compromised.

In the chaotic flow regime, mixing is promoted by stretching and folding of the two liquids streams, as described in classical framework of mixing in chaotic flows (Ottino et al., 1979). From these mixing mechanisms results the formation of a lamellar structure (Lee et al., 1980; Wood et al., 1991; Santos et al., 2008). Figure 2 shows a PLIF image of chaotic flow in CIJs where it is observed that the thickness of the two initial segregated fluid streams, $s$, is reduced by the advection mechanisms. In these mixing devices, due to the short residence time inside the mixing chamber, the molecular diffusion does not occur significantly, prevailing the advection mechanisms.

Lee et al. (1980), Tucker and Suh (1980) and Baldyga and Bourne (1983) proposed different models to estimate the average striation thickness, $s$, in the lamellar structure of the mixture formed in a RIM machine CIJ mixer. The model proposed by Lee et al. (1980) is based on the fact that thinning of the lamellae is two-dimensional and this is caused by incompressible stretching of fluid elements. This model defines a coordinate system, $x$ and $y$, at the interface of the fluid streams being mixed. This Lagrangian approach to the coordinates referential is shown in Figure 2. From these considerations, they obtained

$$
\frac{s}{d}=\left(1+\frac{\operatorname{Re}^{2} v \tau}{2 d^{2}}\right)^{-\frac{1}{2}}
$$

where Re is the Reynolds Number given by Equation (1), $v$ is the kinematic viscosity and $\tau$ is the average residence time in the mixing zone. The average residence time in the mixing zone for impingement of two cylindrical streams in a cylindrical chamber was defined by Lee et al. (1980) as

$$
\tau=\frac{n D^{3}}{\left(1+r_{\mathrm{s}}^{-1}\right) v d \operatorname{Re}}
$$

where $r_{\mathrm{s}}$ is the volumetric flow rate ratio between the two jets, and $n D$ is the distance from the top of the mixing chamber until the point where the dynamic mixing occurs, observed to be $n D \sim 2 D$ to $3 D$ (Kolodziej et al., 1986). Equation (2) describes the decreasing of the average striation thickness of the fluid laminae, $s$, since they are formed in the jets' impingement point until they flow out of the mixing zone after the time $\tau$. The striation thickening described by this model depends on the Reynolds number, the inlet injectors diameter and the physical properties 
of the fluid streams. This model is only valid for chaotic flow regimes where the mechanism for mixing is the stretching of the interface between fluids with corresponding interfacial area generation and striation thickness thinning.

On the other hand, Tucker and Suh (1980) assumed that impingement mixing is fully turbulent. They assumed a Kolmogorov isotropic turbulence description where the striation thickness is determined by Kolmogorov scale, $\lambda_{K}=\left(\frac{v^{3}}{\varepsilon}\right)^{1 / 4}$. From dimensional considerations, Tucker and Suh (1980) obtained

$$
s \propto \frac{d}{\operatorname{Re}^{\frac{3}{4}}}
$$

Baldyga and Bourne (1983) predicted a reduction of scales in the light of statistical theory of turbulent diffusion combined with an exponential residence time distribution of the fluid inside the mixing zone. They considered isotropic and homogeneous turbulent flow at the top of the mixing chamber, and defined the striation thickness as,

$$
\frac{s}{s_{0}}=0.76 E\left(1+2.30 \frac{n^{\frac{4}{3}} \theta^{2}\left(1+r_{\mathrm{s}}^{-3}\right)^{\frac{2}{3}}\left(\frac{D}{d}\right)^{4}}{E^{\frac{4}{3}}\left(1+r_{\mathrm{s}}{ }^{-1}\right)^{2}}\right)^{-\frac{1}{4}}
$$

where $s_{0}$ is the initial striation thickness, $E$ is the proportional factor in the equation $s_{0}=E d, n$ is the number of mixing chamber diameters over which turbulent mixing occurs, $\theta$ is the dimensionless time given by $\theta=\frac{t}{\tau}$ where $r_{\mathrm{s}}$ is the flow rate ratio between the two jets. The initial striation thickness, $s_{0}$, is taken as the injectors' diameter, $s_{0} \sim d$, and thus $E$ is of order 1 .

The flow of reactant fluid streams in CIJs mixing chamber is described by the decreasing of the striation thickness and also by a set of complex interactions between molecular diffusion, chemical reaction and fluid mechanics. Ottino et al. (1979) were the first to describe a mixing model which balances the description of reaction, diffusion and deformation from a Lagrangian point of the view. Kusch et al. (1989) applied this mixing model to CIJs using the striation thickness evolution proposed by Lee et al. (1980) for laminar flow conditions. The numerical results from the mixing model were validated from experimental data of competitive-consecutive azo-coupling reaction where the working fluids had the same physical properties of water.

The actual conditions in RIM machines differ from the experimental work of Kusch et al. (1989) where water was used as working fluid. This motivated the experimental work of Nunes et al. (2012), where the micromixing test reaction of Bourne et al. (1990) was implemented according to the best knowledge on the conditions that promote the best dynamics of chaotic mixing in CIJs: viscous fluids that ensure an adequate dynamics of the flow at low Re and the balancing of the jets. The working fluids used in Nunes et al. (2012) are 20 times more viscous than water. This aimed at narrowing the gap from experiments to industrial RIM machines, where for typical Reynolds numbers, 100 to 500, jets velocities and corresponding Froude numbers are larger and passage times shorter than the ones occurring in water based experimental setups.

CIJs have also been used for other applications than RIM, being the main difference on the geometry above the injectors and at the outlet (Siddiqui et al., 2009; Icardi et al., 2011a). These CIJs have been used for precipitation of nanoparticles (Lince et al., 2009), generally at turbulent flow regimes, and so the modelling of chemical reaction generally resorts to turbulence models (Feng et al., 2005; Liu and Fox, 2006; Gavi et al., 2007a; Gavi et al., 2007b; Liu et al., 2009; Icardi et al., 2011a; Icardi et al., 2011b). 
Another important type of opposed jets mixers are T-jets mixers, with some similarities and differences with CIJs, that are generally made of prismatic mixing chambers with square or circular injectors (Gobby et al., 2001; Engler et al., 2004; Telib et al., 2004; Hoffmann et al., 2006; Bothe et al., 2008; Bothe et al., 2010). Flow regimes in T-jets and the respective comparison to CIJs were reviewed in Santos and Sultan (2013). The main difference between flow patterns and regimes generated in CIJs and T-Jets mixers, stem from the fact that T-jets geometries are characterised by injectors which extend through the entire depth of the mixing chamber and in this way, blocking the radial spreading of the jets as observed in CIJs (Figure 1b).

T-jets have been used more on micro sized devices (Wong et al., 2004; Bothe et al., 2006, 2008; Bothe et al., 2011; Orsi et al., 2013a; Orsi et al., 2013b) and on nanoparticles wet synthesis methods with particular focus to the works from the group of Prof. Peukert (Schwarzer and Peukert, 2004; Gradl et al., 2006; Gradl and Peukert, 2009). The most common configuration of T-jets is the one where square injectors are connected directly to the top of the mixing chamber having widths of $1 / 4$ to $1 / 2$ of the mixing chamber width. For this type of configuration the following operational flow regimes are observed (Engler et al., 2004; Bothe et al., 2006; Soleymani et al., 2007; Dreher et al., 2009):

- stratified flow regimes occurs at $\operatorname{Re}<50$ and are similar to the segregated flow regime of CIJs, with two streams flowing through parallel paths from the inlet injector to the outlet (Engler et al., 2004);

- vortex flow regimes occurs when the stratified flow regimes start to form Dean vortices, but still keeping the flow symmetry (Engler et al., 2004; Bothe et al., 2006; Fani et al., 2013). Mariotti et al. (2018) reports that the vortex flow regime occurs for $80<\operatorname{Re}<$ 140 ;

- engulfment flow regimes occurs at larger Reynolds numbers when the two parallel Dean vortices start to engulf on each other, greatly increasing mixing between flow streams (Engler et al., 2004; Bothe et al., 2006; Fani et al., 2013); engulfment regime occurs for $145<\operatorname{Re}<220$ according to Mariotti et al. (2018).

More recently, Mariotti et al. (2018) and Mariotti et al. (2019) described two new observed unsteady flow regimes generated for larger Reynolds numbers: periodic asymmetric and periodic symmetric regime. In the range $225<R e<320$, the flow presents a periodic motion and is characterised by an asymmetry in the mixing chamber. For $325<\operatorname{Re}<510$, an unsteady and periodic flow is generated, however, this is characterised by a symmetry in the mixing chamber. Since T-jets are micro/milli reactors, the operation conditions are typically from the stratified flow regime to engulfment flow regime (Santos and Sultan, 2013).

The transition between flow regimes in T-jets is not only dependent on the Reynolds number, and Soleymani et al. (2007) proposed an identification number that is dependent on the Re and the reactor geometry. The geometry also affects the configuration of the Dean vortices in T-jets (Andreussi et al., 2015). Furthermore, the inlet flow conditions also affect the mixing in T-jets. (Galletti et al., 2012). The flow scales evolution in T-jets has also been analysed, and it is not directly related with the one in CIJs (Thomas and Ameel, 2010).

The particular T-jets mixers equipped with an headspace, above the injectors, and in the particular designs with expansion ratios (injectors width versus chamber width) larger than 4 , were observed to operate at chaotic flow regimes with vortex shedding dynamics close to the one observed in CIJs (Krupa et al., 2012; Sultan et al., 2012; Sultan et al., 2013; Krupa et al., 2014; Tu et al., 2014a; Tu et al., 2014b; Li et al., 2016).

In this work two approaches are used to study the striation thickness evolution of viscous fluids in CIJs. The Eulerian approach consists in the development of a lamellar micromixing model, 
similar to that one proposed by Ottino et al. (1979). This model was solved using striation thickness data from the models proposed by Lee et al. (1980) and Baldyga and Bourne (1983) and then compared with the experimental data from Nunes et al. (2012). The experimental work of Nunes et al. (2012) used micromixing test reactions in a viscosity range close to polymer processing applications, and so this data is closer to the actual applications than data obtained with water as working fluid ((Kusch et al., 1989)). The main issue with the application of the modelling developed in Ottino et al. (1979) is getting the right description of the stretching field. The model from Lee et al. (1980) assumes the thinning of the lamellae is two-dimensional and this is caused by incompressible stretching of fluid elements, i.e. uses the description of the kinematics of mixing in chaotic flows. The model of Baldyga and Bourne (1983) is based on the statistical description of scales in turbulent flows. On the other hand, the Lagrangian approach consists in the comparison of the data from the striation thickness models and the deformation undergone by material elements obtained from Computational Fluid Dynamics (CFD) simulations. These results will offer further understanding on mixing scales evolution enabling a fully resolved flow scale for the simulation of mixing and chemical reaction in CIJs without the full simulation of the flow field.

\section{Lamellar Micromixing Model}

A complete mechanistic micromixing model describes molecular diffusion, chemical reaction and fluid mechanics in a mixing device. The model presented in this work considers that reaction and diffusion do not affect the fluid properties inside the CIJ mixing chamber. This is applied to the micromixing test reaction of Bourne et al. (1990) because the properties of fluids are not significantly altered by the chemical reaction. This consideration is also valid in RIM machines. In RIM there are viscosity changes with reaction, heat release and adiabatic temperature rising, which is often in the $100^{\circ} \mathrm{C}$ range, however the changes of fluid properties take place only when the mixture is discharged into the mould. This occurs because the residence time in the RIM CIJs ( $\tau \sim 10 \mathrm{~ms}$ ) is not sufficient for the reaction to take place.

The lamellar micromixing model was introduced in late 1970s early 1980s and describes the evolution of chemical species concentration in space and time between two liquids being mixed into a lamellar structure (Ottino et al., 1979; Ranz, 1979; Ottino, 1980). This model takes in account the stretching of the interface between two fluids and the respective increasing of the interfacial area. The ultimate mass transfer mechanism is solely diffusion, as given from Fick's law, but now in a warped space, where warping is determined by the dynamics of mixing in chaotic flows and portrayed by the stretching of the fluids interface which is proportional to the thinning of the mixing lamellar structures. For this micromixing model the coordinate system, $x$ and $y$ is setup at the interface of the two fluids. Figure 2 shows a PLIF image with the proper colocation of the coordinate system at the interface between the two fluids, A and B. From these assumptions, the conservation equation of species $i$ is

$$
\frac{\partial C_{i}}{\partial t}+(\mathbf{D}: \mathbf{n n}) x \frac{\partial C_{i}}{\partial x}=D_{i} \frac{\partial^{2} C_{i}}{\partial x^{2}}+R_{i},
$$

where $\mathbf{D}$ is the stretching tensor and $\mathbf{n}$ is the normal direction of the interface, which corresponds to the direction of the mass transfer (Ottino, 1982). The stretching function is given by $\alpha(\mathbf{X}, t)=$ $-(\mathbf{D}: \mathbf{n n})$ which corresponds to the rate of expansion or contraction around the particle $\mathbf{X}$ (Ottino et al., 1979).

The convective term of Equation (6) can be eliminated by a change of variables. The position $x$ is transformed as $\xi=\frac{x}{s(t)}$ and time $t$ as $\Gamma=\frac{t}{t_{D}}$ where $s(t)$ is the striation thickness evolution and 
$1 \quad t_{D}$ is the diffusion time, $t_{D}=\frac{s_{0}{ }^{2}}{D_{m}}$ wherein $D_{m}$ is the molecular diffusion coefficient. From this

2 change of variables, the species conservation equation takes the form

$$
\frac{\partial C_{i}}{\partial \Gamma}=\left(\frac{s_{0}}{s(\Gamma)}\right)^{2} \frac{\partial^{2} C_{i}}{\partial \xi^{2}}+t_{D} R_{i}
$$

3 The model as expressed in Equation (7) takes in account the stretching of fluids and the respective 4 increasing of the interfacial area in the first right hand side term. Deformation induces two effects 5 on diffusion: it increases the interfacial area for diffusion and, on the other hand, it wraps the 6 diffusional distance by the striation thinning term $\xi=\frac{x}{s(t)}$. This results in enhanced diffusion 7 through the fluids interface. Furthermore, the concentration profile is also changed by the reaction 8 term, the second one in right hand side of Equation (7).

\section{Application to Experimental Data}

10 The LM model was applied to the same operational conditions and CIJs configuration of the experimental work in Nunes et al. (2012) where the micromixing process in a pilot RIM machine was studied using a test reaction system. The experimental set-up is described in Nunes et al. (2012). The setup consists of a mixing chamber and two injectors drilled in a single plexiglass glass. The mixing chamber has a diameter $D=10 \mathrm{~mm}$, a height $H=50 \mathrm{~mm}$ and a head space $h=5 \mathrm{~mm}$. Two opposed cylindrical injectors with a diameter $d=1.50 \mathrm{~mm}$ are placed at $5 \mathrm{~mm}$ from the mixing chamber closed top. Each injector is fed through a tank with a pump. At the outlet of the mixing chamber, the fluid is discharged into a transparent mould.

The test reaction system carried out by Nunes et al. (2012) is the simultaneous coupling of 1naphtol, $A_{1}$, and 2-naphtol, $A_{2}$, with diazotized acid, B, (Bourne et al., 1990)

$$
\begin{aligned}
& \mathrm{A}_{1}+\mathrm{B} \stackrel{k_{1}}{\rightarrow} \mathrm{R} \\
& \mathrm{R}+\mathrm{B} \stackrel{k_{2}}{\rightarrow} \mathrm{S} \\
& \mathrm{A}_{2}+\mathrm{B} \stackrel{k_{3}}{\rightarrow} \mathrm{Q}
\end{aligned}
$$

The experiments were performed injecting the limiting reactant, diazotized acid, $\mathrm{B}$, from one injector while the other injector delivered 1-naphtol, $A_{1}$, and 2-naphtol, $A_{2}$. The working conditions are symmetric, i.e, same viscosity, density and flow rate in both injectors. The density of reactants corresponds to the density of water, $\rho=1000 \mathrm{~kg} \mathrm{~m}^{-3}$, at $T=20^{\circ} \mathrm{C}$.

The experiments were carried out using aqueous solutions with viscosity $\mu=20 \mathrm{mPa} \cdot \mathrm{s}$ at $20^{\circ} \mathrm{C}$. Rheolate 255 was used as thickener to achieve the desired viscosity. Baldyga and Bourne (1999), Bourne et al. (1985) and Gholap et al. (1994) concluded that the amount of Rheolate 255 added to reactant solutions does not affect the kinetics parameters: $k_{1}=14 \times 10^{3} \mathrm{~m}^{3} \mathrm{~mol}^{-1} \mathrm{~s}^{-1}, k_{2}=$ $2.56 \mathrm{~m}^{3} \mathrm{~mol}^{-1} \mathrm{~s}^{-1}$ and $k_{3}=95 \mathrm{~m}^{3} \mathrm{~mol}^{-1} \mathrm{~s}^{-1}$ at $T=20^{\circ} \mathrm{C}$ (Nunes et al., 2012). These kinetic constants mean that the first reaction in Equation (8) is much faster than the second one and even than the third one. This results on the maximum yield of $R$ when the injected reactants, $A_{1}$ and $B$, are completely mixed in a shorter time than the second reactional step.

Since the reactant B is the limiting reactant, Nunes et al. (2012) measured the product distribution from the fraction of reactant $B$ that is converted to $S$ and Q, i.e., from the reaction selectivities. The selectivities $X_{\mathrm{Q}}$ and $X_{\mathrm{S}}$ depend on the reactant combination and are defined as, 


$$
\begin{aligned}
& X_{\mathrm{S}}=\frac{2 C_{\mathrm{S}}}{C_{\mathrm{R}}+C_{\mathrm{Q}}+2 C_{\mathrm{S}}} \\
& X_{\mathrm{Q}}=\frac{C_{\mathrm{Q}}}{C_{\mathrm{R}}+C_{\mathrm{Q}}+2 C_{\mathrm{S}}}
\end{aligned}
$$

1 The final products concentrations, $C_{\mathrm{R}}, C_{\mathrm{Q}}$ and $C_{\mathrm{S}}$, achieved in Nunes et al. (2012) can be compared 2 with the numerical simulation results obtained from LM model by solving a PDE system for each 3 species. When the LM model is applied to the test reaction system of Bourne et al. (1990) 4 (Equation (8)), the resulting a system of six PDEs is given by

$$
\left\{\begin{array}{l}
\frac{\partial A_{1}}{\partial \Gamma}=\eta^{2}(\Gamma) \frac{\partial^{2} A_{1}}{\partial \xi^{2}}-\mathrm{Da} A_{1} B \\
\frac{\partial A_{2}}{\partial \Gamma}=\eta^{2}(\Gamma) \frac{\partial^{2} A_{2}}{\partial \xi^{2}}-\mathrm{Da} \varepsilon_{2} A_{2} B \\
\frac{\partial B}{\partial \Gamma}=\eta^{2}(\Gamma) \frac{\partial^{2} B}{\partial \xi^{2}}-\mathrm{Da}\left(\beta_{1} A_{1} B+\beta_{1} \varepsilon_{1} B R+\beta_{2} \varepsilon_{2} A_{2} B\right) \\
\frac{\partial R}{\partial \Gamma}=\eta^{2}(\Gamma) \frac{\partial^{2} R}{\partial \xi^{2}}+\operatorname{Da}\left(A_{1} B-\varepsilon_{1} B R\right) \\
\frac{\partial S}{\partial \Gamma}=\eta^{2}(\Gamma) \frac{\partial^{2} S}{\partial \xi^{2}}+\operatorname{Da}_{1} B R \\
\frac{\partial Q}{\partial \Gamma}=\eta^{2}(\Gamma) \frac{\partial^{2} Q}{\partial \xi^{2}}+\operatorname{Da}_{2} \frac{\beta_{2}}{\beta_{1}} A_{2} B
\end{array}\right.
$$

$6 \quad$ where $A_{1}=\frac{C_{\mathrm{A}_{1}}}{C_{\mathrm{A}_{1,0}}}, B=\frac{C_{\mathrm{B}}}{C_{\mathrm{B}, 0}}, A_{2}=\frac{C_{\mathrm{A}_{2}}}{C_{\mathrm{A}_{2,0}}}, \quad R=\frac{C_{\mathrm{R}}}{C_{\mathrm{A}_{1,0}}}, S=\frac{C_{\mathrm{S}}}{C_{\mathrm{A}_{1,0}}}, Q=\frac{C_{\mathrm{Q}}}{C_{\mathrm{A}_{1,0}}}, \eta=\frac{s_{0}}{s(\Gamma)}, \quad \beta_{1}=\frac{C_{\mathrm{A} 1,0}}{C_{\mathrm{B}, 0}}$, $7 \quad \beta_{2}=\frac{C_{\mathrm{A} 2,0}}{C_{\mathrm{B}, 0}}, \varepsilon_{1}=\frac{k_{2}}{k_{1}}$ and $\varepsilon_{2}=\frac{k_{3}}{k_{1}}$. Da $=\frac{t_{D}}{t_{R}}$ is the Damköhler number and $t_{R}=\frac{C_{\mathrm{A} 1,0}}{k_{1} C_{\mathrm{A} 1,0} C_{\mathrm{B}, 0}}$ is the 8 reaction time.

Equation (11) describes the changes of molar fraction of each species in the normal direction of the interface when a lamellar structure is formed by the impingement of the reactants in the CIJ mixing chamber. Reactant $B$ is injected from one injector and, $A_{1}$ and $A_{2}$ are injected from the other one, so the initial mixing conditions correspond to the complete initial segregation of the reactants,

$$
\Gamma=0, \quad A_{1}=A_{2}=\mathrm{H}(\xi) ; B=\mathrm{H}(-\xi) ; R=Q=S=0 \text { for } \xi \in[-0.5,0.5]
$$

where $H(\xi)$ is a Heaviside function, which coincides with the mixing chamber's axis. The boundary conditions correspond to the gradient of concentrations at the boundaries of a single stria, $\xi=-0.5$ and $=0.5$, which is equal to 0 ,

$$
\Gamma>0, \quad \frac{\partial A_{1}}{\partial \xi}=\frac{\partial A_{2}}{\partial \xi}=\frac{\partial B}{\partial \xi}=\frac{\partial R}{\partial \xi}=\frac{\partial Q}{\partial \xi}=\frac{\partial S}{\partial \xi}=0 \text { for } \xi= \pm 0.5
$$

The PDE system, Equation (11), was solved using an algorithm developed in Matlab based on the PDE solver pdepe. This solver uses the finite element method (FEM) to solve initial-boundary value problems for parabolic-elliptic PDEs.

The initial concentrations $\left(C_{\mathrm{A}_{1}, 0}, C_{\mathrm{B}, 0}, C_{\mathrm{A}_{2}, 0}\right)$ set as initial conditions of $\mathrm{LM}$ model correspond to half of the concentration in the feed concentrations summarized in Table 1. Table 1 also shows 
1 the stoichiometric ratios, $\gamma_{\mathrm{A}_{1}}=\frac{C_{\mathrm{A}_{1}, 0}}{C_{B, 0}}$ and $\gamma_{\mathrm{A}_{2}}=\frac{C_{\mathrm{A}_{2}, 0}}{C_{A_{1}, 0}}$, for each experiment and the respective reaction time, $t_{\mathrm{R}}$. This set of working conditions corresponds to the experimental plan carried out by Nunes et al. (2012). The first two experiments, \#1 and \#2, were performed to evaluate the reproducibility of the experimental method. In experiments \#1 to \#4, $A_{1}$ and $B$ concentrations were kept constant and $\mathrm{A}_{2}$ concentration was decreased in order to study the micromixing at different $\gamma_{\mathrm{A}_{2}}$ values and reaction times. In experiments $\# 5$ to $\# 7$, lower concentrations of $A_{1}$ and $\mathrm{B}$ were tested for longer reaction times.

The diffusion coefficient, $D_{m}$, used in the numerical calculations was estimated from data presented in literature. According to Stokes-Einstein equation, the diffusion coefficient decreases with the increasing of the fluid viscosity. So, the diffusion coefficient was estimated considering that the diffusivity is less than the characteristic diffusivity in water. According to Delgado and Guedes de Carvalho (2001), the diffusivity of naphthol in water is $D_{m}=1.04 \times 10^{-9} \mathrm{~m}^{2} \mathrm{~s}^{-1}$ at $T=20^{\circ} \mathrm{C}$. Therefore, the influence of the diffusional coefficient was studied in the range between $1.04 \times 10^{-9} \mathrm{~m}^{2} \mathrm{~s}^{-1}$ and $1 \times 10^{-10} \mathrm{~m}^{2} \mathrm{~s}^{-1}$.

The LM model was solved using the model of Lee et al. (1980) (Equation (2)) or the model of Baldyga and Bourne (1983) (Equation (5)) to estimate the striation thickness evolution, $\eta=\frac{s_{0}}{s(\Gamma)}$, which is taken in account in the first term of the right hand side of Equation (11). The initial striation thickness, $s_{0}$, is equal to the injectors' diameter, $s_{0} \sim d$. When the model of Baldyga and Bourne (1983) is used, the length of the mixing chamber where chaotic mixing occurs has to be specified. According to Kolodziej et al. (1982), the most active mixing region in CIJs is around the jets' impingement point up to a distance of $2 D$ to $3 D$ from the mixing chamber top. Therefore, the term $n D$ in the model of Baldyga and Bourne (1983) is $n D=2 D$. Table 2 summarizes the lamellar model parameters used in numerical calculations.

\section{Results and Discussion}

First, the LM model was solved using the striation thickness function proposed by Lee et al. (1980). This function is only valid for chaotic flow regimes that occur for Reynolds numbers Re $>150$ (Santos et al., 2008). The LM model was solved for the initial working conditions presented in Table 1 and for Reynolds numbers ranging from 150 to 700 . The final products concentrations obtained from the LM model give the selectivity $X_{\mathrm{Q}}$ from Equation (8).

Figure 3 shows the selectivity $X_{\mathrm{Q}}$ as a function of Reynolds number for experiments \#1 and \#2 of

Table 1 and the corresponding predictions using Lee et al. (1980) model for three different diffusion coefficient values, $D_{m}=1.04 \times 10^{-9} \mathrm{~m}^{2} \mathrm{~s}^{-1}, D_{m}=5 \times 10^{-10} \mathrm{~m}^{2} \mathrm{~s}^{-1}$ and $D_{m}=$ $1 \times 10^{-10} \mathrm{~m}^{2} \mathrm{~s}^{-1}$. This figure illustrates the sensibility of the LM model to the diffusion coefficient.

Figure 3 shows that $X_{\mathrm{Q}}$ decreases with the Reynolds number. This means that when the Reynolds number is increased, the microscale homogenization becomes faster and so the conversion of $\mathrm{B}$ favours the reactions with faster kinetics, resulting in the decrease of the formation of Q and $\mathrm{S}$. From Figure 3, it is also observed that the LM model is quite sensitive to the diffusion coefficient chosen. The diffusion coefficient $D_{m}=5 \times 10^{-10} \mathrm{~m}^{2} \mathrm{~s}^{-1}$ gives the best estimation of the actual diffusivity. Based on this observation, the diffusional coefficient $D_{m}=5 \times 10^{-10} \mathrm{~m}^{2}$ was set in the following LM model simulations.

The LM model numerical validation comprised the analysis of time and space discretization scales effect on $X_{\mathrm{Q}}$ curve. The range of studied parameters showed no influence in the LM model results. Therefore, the same number of intervals in time discretization, $n_{t}=500$, and in space discretization, $n_{x}=500$, were set in all LM model simulations. 
Nunes et al. (2012) used the average $X_{\mathrm{Q}}$ curve obtained from experiments \#1 and \#2 as the base case for comparison with the results of experiments \#3 and \#4 of Table 1 . The difference between experiments \#2, \#3 and \#4 is the initial naphtol ratios, $\gamma_{\mathrm{A}_{2}}$. Figure 4 shows $X_{\mathrm{Q}}$ as a function of Reynolds number for these experimental conditions and the corresponding predictions using the striation function of Lee et al. (1980). This figure shows that the experimental data is well described by the lamellar micromixing model mainly for Re $>200$. Experiment \#3 presents a small deviation from the LM model, however the numerical results are within the uncertainty associated to the experiments. At lower Reynolds number or larger ratios of concentrations the condition that, at the sampling point in the center of the CIJs outlet, all the limiting reagent was consumed is more difficult to guarantee. So, these points are generally more prone to experimental deviations.

Figure 5 shows $X_{\mathrm{Q}}$ as a function of Reynolds number for experiments \#5, \#6 and \#7, associated to longer reaction times, and the corresponding simulations using the model of Lee et al. (1980). The concentrations of reactants were decreased in experiments \#5, \#6 and \#7. From Figure 5, it is observed that the LM model gives a good prediction of experiments \#5 to \#6 within the uncertainty associated to the experiments, however a small deviation is observed for experiment \#7 model for $\mathrm{Re}>300$. For this range of Reynolds numbers, the selectivity obtained from experimental data is $X_{\mathrm{Q}} \sim 0$, which may be related with the concentration detection threshold of the experimental method.

Figure 4 and 5 show the good agreement between experimental data and LM model results, which means that the model proposed by Lee et al. (1980) gives an accurate estimation for the reduction of the striation thickness in CIJ mixing chamber. Moreover, Figures 4 and 5 show that the LM model accurately predicts the experimental data when the diffusion coefficient is $D_{m}=$ $5 \times 10^{-10} \mathrm{~m}^{2} \mathrm{~s}^{-1}$. Therefore, this value is a good estimation for the actual diffusivity.

A second analysis was done by solving the LM model using the striation thickness function proposed by Baldyga and Bourne (1983). This striation function is based on the statistical theory of turbulent diffusion.

Figure 6 shows $X_{\mathrm{Q}}$ as a function of Reynolds number for experiments \#2 to \#4 and the solution of LM model using the striation functions of Baldyga and Bourne (1983) and Lee et al. (1980). Experiment \#2 data is in Figure 6a and experiments \#3 and \#4 in Figure 6b. Figure 6 shows that for experiments \#2 to \#4 the model from Lee et al. (1980) clearly makes a better description of the experimental results.

For higher Reynolds numbers, $\operatorname{Re}>500$, dynamic mixing structures, characteristic of turbulent flow, are formed and thus the model of Baldyga and Bourne (1983), which is based on turbulence assumption, will most likely describe better the experimental data. Figures $6 \mathrm{a}$ and $6 \mathrm{~b}$ actually show that the LM results using the Baldyga and Bourne (1983) striation function and experimental data for $\mathrm{Re} \gg 500$ are in agreement. However, further experimental data for larger Reynolds numbers would be required to demonstrate this.

In conclusion, the striation thickness function proposed by Lee et al. (1980) gives the best estimation of the striation thickness evolution for Reynolds numbers at which the self-sustainable laminar chaotic flow regime is fully established, $200<\operatorname{Re}<600$. This presents the definite proof that, from micromixing data, the flow in the studied range of Reynolds numbers for CIJs is laminar. Thus, the mechanism of mixing in CIJs is the stretching of the interface between fluids as described in chaotic mixing for laminar flows (Ottino et al., 1979). 


\section{3D CFD Simulation}

2 The mixing length scales and stretching properties of the flow in CIJs were studied from 3D CFD 3 simulations. Lagrangian tracking of passive material fluid elements was made over 3D CFD flow 4 simulations of the CIJs. The fluid elements are described from two particles, which are used to 5 track its position and to measure their stretching history.

6 The CIJ mixing chamber used in CFD simulations have the same dimensions of pilot RIM 7 machine used in Nunes et al. (2012). Figure 7 shows a schematic representation of the CFD 8 geometrical domain and its dimensions. Likewise, the experimental CIJs, the domain consists of 9 a confined mixing chamber with a diameter $D=10 \mathrm{~mm}$ and a height $H=50 \mathrm{~mm}$. Two opposed 10 jets issue from two cylindrical injectors into the cylindrical chamber at $5 \mathrm{~mm}$ from the top. The axis of the two opposed are coincident and perpendicular to the mixing chamber axis. The injectors have a diameter $d=1.5 \mathrm{~mm}$ and a length $=2.5 \mathrm{~mm}$.

The 3D flow of an incompressible fluid inside the RIM machine's mixing chamber was simulated using ANSYS Fluent to solve the equations for mass conservation,

$$
\nabla \cdot \mathbf{u}=0
$$

and momentum conservation,

$$
\rho\left(\frac{\partial \mathbf{u}}{\partial t}+\mathbf{u} \cdot \nabla \mathbf{u}\right)=-\nabla p+\mu \nabla^{2} \mathbf{u}
$$

where $p$ is the pressure and $\mathbf{u}$ is the velocity vector.

The boundary conditions imposed were no-slip condition at the chamber walls, $\mathbf{u}=0$, and constant pressure $p=p_{0}=1$ bar at the outlet. The two working fluids had the same density and viscosity: $\rho=1000 \mathrm{~kg} \mathrm{~m}^{-3}$ and $\mu=20 \mathrm{mPa} \cdot \mathrm{s}$.

Figure 7 shows a wall normal to the injectors axis that divides the mixing chamber in two halves. The wall is only activated to converge an initial symmetric solution of the flow in steady state conditions (Santos et al., 2010). Whenever the wall is activated, no normal velocity components and no shear stress forces conditions are imposed at the symmetric wall.

CFD simulations were initially performed at steady state, i.e., the transient term of Equation (15) was set as zero. For the steady state simulations, the symmetry wall (see Figure 7) was activated. The Third-Order MUSCL scheme was used to discretize the advective terms for momentum and the Standard scheme for pressure. The pressure-velocity coupling scheme was computed with PISO and gradients were solved with the Least Squares Cell Based scheme.

The dynamic flow simulations were started from the steady-state simulations by removing the symmetry wall and imposing a perturbation time function $(f)$ to only the left injector, aiming to onset the growth of the chaotic instabilities in a reproducible manner. The boundary condition at the left inlet was set as 


$$
\mathbf{u}=-2 v_{\mathrm{inj}} \frac{\left(\frac{d}{2}\right)^{2}-r^{2}}{\left(\frac{d}{2}\right)^{2}} f(t / \tau) \mathbf{n}
$$

where $\tau$ is the chamber residence time defined by Equation (3) and $f$ is the perturbation time function, given by $f(t / \tau)=1+\frac{a}{2}(1-H(t / \tau-b))\left(1-\cos \left(\frac{2 \pi}{b} t / \tau\right)\right)$, where $H(t)$ is the Heaviside function. The parameter $a$ is the maximum amplitude of the perturbation, which was set as $a=0.1$. The parameter $b=0.1$ is the number of mean residence times over which the perturbation is applied. This perturbation time function has been previously used by Teixeira (2000) and Santos (2003), who concluded that it does not induce any discontinuity in the flow or new dynamic behaviours. The $2 \mathrm{D}$ validation of the transient simulation parameters was made by Santos et al. (2009).

In transient simulation, the Second Order Implicit formulation was used to discretize the transient term of Equation (15) and the time step between iterations was set at a Courant number $C_{N} \leq 1$ ensuring stability of the solutions.

The CFD simulation of the CIJs were fully-resolved regarding the hydrodynamic scales and time, and so no subgrid scale models are applied. These CFD results were validated regarding the flow patterns and its dynamics from experimental work with Laser Doppler Anemometry, Particle Image Velocimetry and PLIF in Santos et al. (2009) and from PLIF in Gonçalves et al. (2017).

\section{Particle Tracking and Stretching}

The stretching of the flow was studied from a Lagrangian approach by tracking the position and deformation of spherical material elements in the flow. The particle trajectories were obtained by the integration of the advection equation,

$$
\frac{\mathrm{d} \mathbf{x}}{\mathrm{d} t}=\mathbf{u}(\mathbf{x}, t)
$$

where $\mathbf{u}$ is the velocity vector and $t$ is the flow time. The initial position of each particle corresponds to $\mathbf{x}(t=0)=\mathbf{X}$.

The deformation gradient tensor $\mathbf{F}$ is computed from the particles in fluid elements as,

$$
\mathbf{F}(\mathbf{X}, t)=\frac{\mathrm{d} \mathbf{x}(\mathbf{X}, \mathrm{t})}{\mathrm{d} \mathbf{X}}
$$

F can be obtained from

$$
\frac{\mathrm{d}}{\mathrm{d} t} \mathbf{F}=(\nabla \mathbf{u})^{\mathrm{T}} \cdot \mathbf{F}
$$

where the initial condition is $\mathbf{F}(t=0)=\mathbf{I}$ wherein $\mathbf{I}$ is the identity tensor (Ottino, 1990).

Locally, the deformation of the element is given by 


$$
\lambda=\sqrt{\mathbf{C}: \mathbf{M M}}
$$

1 where $\mathbf{M}$ is calculated by $\mathbf{M}=\frac{\mathrm{d} \mathbf{X}}{|\mathrm{d} \mathbf{X}|}$ and $\mathbf{C}$ is the right Cauchy-Green deformation tensor that is 2 given by $\mathbf{C}(t)=\mathbf{F}(t) \cdot \mathbf{F}(t)^{\mathrm{T}}$. Therefore, for $0<\lambda<1$ the system is compressed, while for $\lambda>$ 31 it is stretched.

4 In this work, a cluster of 172 particles was injected in the transient flow from each injector, total 5 of 344 for both jets, at $t=3 \tau$. The particles were tracked by integration of the advection up to 6 the time when the first injected particle leaves the chamber. The particles have the same physical 7 properties of the fluid in order to be passive and not perturb the flow. Each particle position was 8 calculated integrating the advection equation with a sixth order Runge-Kutta scheme available in 9 Fluent. The position of particles, velocity components and velocity gradient were imported from Fluent and the deformation was computed with an algorithm made in Matlab.

\section{Prediction of Striation Thickness Distribution}

The striation thickness distribution in the flow can be predicted from the stretching distribution of elements in the mixing chamber. For that, two randomly particles, $\alpha$ and $\beta$, placed at one of the inlets are initially separated by an infinitesimal distance $\mathrm{d} R$. Then the particles are transported by the flow and stretching flow tends in average to separate the two particles by a distance $d r$. In Figure 8, a fluid element $\mathrm{d} X_{1} \mathrm{~d} X_{2} \mathrm{~d} X_{3}$ with two points $\alpha$ and $\beta$ in opposed diagonal vertices is shown. For $t=0$, the initial distance between the two particles is given by

$$
\mathrm{d} R^{2}=\mathrm{d} \mathbf{X} \cdot \mathrm{d} \mathbf{X}
$$

If the initial dimensions are $s_{0}=\mathrm{d} X_{1}=\mathrm{d} X_{2}=\mathrm{d} X_{3}$, Equation (21) becomes

$$
\mathrm{d} R=\sqrt{3} s_{0}
$$

Since the particles are transported in the flow, the fluid element will be stretched in the principal direction of deformation. As Figure 8 shows, for $t>0$ the distance between particles $\alpha$ and $\beta$ is given by

$$
\mathrm{d} r^{2}=\mathrm{d} \mathbf{x} \cdot \mathrm{d} \mathbf{x}
$$

For $t \gg 0$, the fluid element will no longer resemble a prism but instead it will resemble a thin filament. At that moment, $\mathrm{d} x_{3} \gg s_{0}>\left(\mathrm{d} x_{1}, \mathrm{~d} x_{2}\right)$ and thus it can be assumed that

$$
\mathrm{d} r^{2}=\mathrm{d} x_{3}{ }^{2}
$$

For incompressible fluid flow, $\nabla \cdot \mathbf{u}=0$, the volume of the fluid element, $\left(\mathrm{d} x_{1} \mathrm{~d} x_{2} d x_{3}\right)$, at $t=0$ is kept for long deformation times by

$$
\mathrm{d} x_{1} \mathrm{~d} x_{2} d x_{3}=s^{2} \mathrm{~d} x_{3}=s_{0}{ }^{3}
$$

where $\mathrm{d} x_{1}$ and $\mathrm{d} x_{2}$ are replaced by the fluid filament thickness, or by the striation thickness, $s$. The evolution of the distance between the two particles, $\mathrm{d} r$, is related with the stretching function 


$$
\mathrm{d} r(t) \sim \lambda(t) \mathrm{d} R
$$

2 Replacing Equations (20), (24) and (26) in Equation (25), it results in

$$
\sqrt{3} \lambda s_{0} s^{2}=s_{0}{ }^{3}
$$

4 Therefore, the striation thickness of a particle initially at position $\mathbf{X}$ can be estimated from

$$
s(\mathbf{X}, t)=(\sqrt{3} \lambda(\mathbf{X}, t))^{-\frac{1}{2}} s_{0}
$$

6 where the initial striation thickness, $s_{0}$, is close to the injectors' diameter, $s_{0} \approx d$.

7 The effect of diffusion and reaction is not considered in this calculation of the striation thickness

8 distribution.

\section{$9 \quad$ Results and Discussion}

\section{Flow Field}

CFD simulations were performed at dynamic flow simulations from $t=0$ to $t=3 \tau$. The results of 3D CFD simulations were used to display the streamlines of the flow and the strain rate field in CIJs mixing chamber. Figures 9, 10 and 11 show a dynamic sequence of top and front views of non-dimensional rate of strain field and the streamlines for $\operatorname{Re}=100, \operatorname{Re}=110$ and $\operatorname{Re}=$ 200 at $t=0$ and $t=3 \tau$. The spatial distribution of the stretching potential in flow is presented using the non-dimensional rate of strain, $\zeta$, which is defined as

$$
\zeta=\frac{1}{2} \frac{(\mathbf{D}: \mathbf{D})^{\mathbf{1} / 2}}{\dot{\gamma}_{\text {injector }}}
$$

where $1 / 2(\boldsymbol{D}: \boldsymbol{D})^{1 / 2}$ is the norm of the rate of strain tensor at each point and $\dot{\gamma}_{\text {injector }}$ is the strain rate experienced by the fluid at the injector's wall and given by $\dot{\gamma}_{\text {injector }}=\frac{8 \mu}{\rho d^{2}} \operatorname{Re}$.

Figures 9a, 10a and 11a show the rate of strain field and the respective streamlines for $t=0$ while Figures $9 \mathrm{~b}, 10 \mathrm{~b}$ and $11 \mathrm{~b}$ correspond to the instant $t=3 \tau$. For each instant and Reynolds number, the non-dimensional rate of strain field is presented in the left hand side figure while the streamlines are shown in right hand side figure.

Figures 9, 10 and 11 show that the rate of strain decreases quickly by several orders of magnitude, from the jets inlet to the outlet. And thus, three main regions are identified from these figures:

- $\quad 0.1<\zeta<1$ in the region of the jets and the manifold resultant of the jets impingement;

- $0.01<\zeta<0.1$ in the remaining volume from the top of the chamber until a distance $\sim 2 D$ from the top;

- $\quad \zeta<0.01$ from a distance $\sim 2 D$ from the top until the outlet. It is observed a larger deformation close to the chamber walls and practically no deformation in the centre.

From the strain rate fields presented in Figures $9 a$ and $9 b$, it is observed that, the flow presents the same strain field at $t=0$ and $t=3 \tau$. For $R e \geq 110$ (Figures 10a and 10b), the flow is similar to the symmetric state but starts to exhibit some oscillation of the jets' impingement surface. And 
for $\operatorname{Re}=200$, the deformation of the jets' impingement surface is increased as shown in the images of strain rate field displayed in Figure 11a and 11b.

Figures 9, 10 and 11 also show the streamlines of the flow. Figures 9a shows that the streamlines of each fluid remain in each side of the mixing chamber at $t=0$. The main feature of this flow is the impingement of the two opposed jets at the mixing chamber axis. After the impingement point the flow spreads radially in the normal direction to the jets' axes and forms two vortices, one around each jet. For $t=3 \tau$ and $\mathrm{Re}=100$ (Figure 9b), the system recovers from the initial perturbation into a state close to the symmetric flow. The interfacial area generated between the two fluids coincides with the axial section of the mixing chamber axis that is normal to the injectors' axis, for both instants.

When the Reynolds number is increased to $R e=110$ (Figures 10a and 10b), streamlines show that the flow does not fully recover from the perturbation exhibiting some deformation of the jets' impingement surface. This is associated to an unsteady flow regime. The streamlines show that the flow becomes nearly parallel after a distance $\sim 2 D$ from the top chamber wall.

From Figures 11a and 11b it is observed the formation of complex streamlines patterns in the top view of the mixing chamber for $\mathrm{Re}=200$. The two recirculation vortices around the jets are no longer observed in the instantaneous flow. The flow rapidly becomes nearly parallel for a distance circa $1.5 \mathrm{D}$ to $2 \mathrm{D}$ from the top. This behaviour of flow is in accordance with Laser Doppler Anemometry experiments presented by Teixeira (2000), where the velocity fluctuations in the mixing chamber decrease by one order of magnitude from the jets impingement point to regions located at $1.5 D$ downstream in the chamber.

\section{Particle Distribution}

The cluster of 344 passive particles introduced in the flow were tracked for $\operatorname{Re}=100, \operatorname{Re}=110$ and $R e=200$. Figures 12,13 and 14 show a dynamic sequence of top and front views of the particles being transported in the mixing chamber for $\operatorname{Re}=100, \operatorname{Re}=110$ and $\operatorname{Re}=200$, respectively.

Figure 12 shows the injection of passive particles for $\mathrm{Re}=100$. This figure shows that, after the impingement point, the particles are spread radially, relatively to the jets' axes. Since a steady flow is achieved under these conditions, particles injected from the right injector remain in the right side of the chamber until the outlet, while particles injected from the left injector remain in the left side.

When the Reynolds number is increased to $\mathrm{Re}=110$ (Figure 13), particles are spread radially. Due to the deformation of the two jets' impingement surface, material is exchanged between the right and left sides of the chamber. These results are in agreement with the streamlines obtained from CFD simulations (Figures 10a and 10b).

For $\operatorname{Re}=200$ (see Figure 14), particles are also transported by the jets from the inlet to the centre of the chamber where they are spread radially. For these flow conditions, the jet's impingement manifold is highly deformed. A homogeneous field of particles is observed at early stages of the particles' trajectories inside the mixing chamber.

Flows developed at $\operatorname{Re}=110$ and $\operatorname{Re}=200$ enable the mixing of material injected from the two sides of the mixing chamber. This fact shows the importance of achieving a dynamic flow regime in impingement jets mixing. And therefore, the hydrodynamic instability plays an important role on the spatial distribution of the two feed streams in the chamber. 


\section{Stretching Histories and Striation Thickness Distribution}

The stretching experienced by each material fluid element was computed for $\operatorname{Re}=100,110,200$ and 300 from the flow strain properties extracted along the trajectories of particles. Figure 15 shows the average stretching, $\langle\lambda\rangle$, as a function of time and the Reynolds number. The average stretching is calculated from

$$
\langle\lambda(t / \tau)\rangle=\frac{1}{N_{\text {particles }}} \sum_{i=1}^{N_{\text {particles }}} \lambda_{i}(t / \tau)
$$

where $N_{\text {particles }}$ is the number of injected particles.

Figure 15 shows that for $\mathrm{Re}=100$, the elements undergo a linear average stretching for longer times. Although the flow is unsteady for $\mathrm{Re}=110$, it is also observed that the elements experience a linear stretching. For $\operatorname{Re}=200$ and $R e=300$, the average stretching increases nearly exponentially with time. At these flow regimes, the dynamics structures enhance the mixing of the two streams delivered by the two opposed injectors. The exponential increase of the average stretching with time is actually a feature of chaotic flows.

The striation thickness of each fluid element was calculated from Equation (28). Figure 16 shows the cumulative striation thickness distribution function at the moment the first particle leaves the mixing chamber, for $\mathrm{Re}=100,110,200$ and 300. The striation thickness distribution predicted by the model of Baldyga and Bourne (1983) (Equation (5)) is also plotted in Figure 16. The parameters used in the model of Baldyga and Bourne (1983) are the dimensions of the mixing chamber (see Figure 7), the flow rate ratio between jets, $r_{s}=1$, and the mixing length in terms of mixing chamber diameters, $n=2.5$. Figure 16 shows that more than half of the strias have thicknesses smaller than $10 \mu \mathrm{m}$, for Re $>110$.

The experimental determination of micromixing time from chemical methods requires that the reaction time is less than the micromixing time (mixing-controlled regime). In this regime, the reaction time is limited by mixing and not by reaction kinetics. In the CFD results presented in this work, where mixing scales have thicknesses smaller than $10 \mu \mathrm{m}$, the micromixing time must be set in the range between the diffusional times and the convective time sufficient to achieve a mixing scale of $s=10 \mu \mathrm{m}$. Considering that the diffusion coefficient between two liquid streams is of the order of magnitude $10^{-9} \mathrm{~m}^{2} \mathrm{~s}^{-1}$, the mixing scales of $10 \mu \mathrm{m}$ set the diffusion times $t_{D}=\frac{s^{2}}{D_{m}} \approx 100 \mathrm{~ms}$. Furthermore, Figure 15 shows that at $\mathrm{Re}=300$ the striation thickness $s=$ $10 \mu \mathrm{m}$ corresponds to $\ln (\lambda)=\ln \left(s_{0} / s\right) \approx 5$ (Ranz (1979)), which is achieved at $t / \tau \approx 0.025$ $(t \approx 10 \mathrm{~ms})$. These results show that at $10 \mathrm{~ms}$ the mixing scale is already sufficient for diffusion mixing times of $100 \mathrm{~ms}$ and therefore, the micromixing time is $10 \mathrm{~ms}<t_{\text {micromixing }}<100 \mathrm{~ms}$. Micromixing test reactions of Nunes et al. (2012) (see Table 1) show that experiments \#2, \#3 and \#4 are sensitive to the micromixing because its reaction time is $21 \mathrm{~ms}$.

Figure 17 shows the mean average striation thickness obtained from CFD simulations. These results are compared with the values predicted by the striation thickness functions presented in the literature: the model of Lee et al. (1980) (Equation (2)), the model of Baldyga and Bourne (1983) (Equation (4)) and the model of Tucker and Suh (1980) (Equation (5)). A self-sustained laminar chaotic flow regime is fully established only for Re above the critical Reynolds number ( $\operatorname{Re}>150)$ and for this flow regime, the order of magnitude of the average striation scale is close to the values predicted by Lee et al. (1980). 
CFD results presented in Figure 17 and the LM model results show that the striation thickness function proposed by Lee et al. (1980) gives the best estimation of striation thickness reduction in CIJ mixing chamber in laminar flow regime range.

\section{Conclusions}

5 This paper presents an analysis of the lamellar microstructure generated by impinging jets flows, 6 with application to RIM machines. A lamellar micromixing model was solved using striation 7 thickness data from the models proposed by Lee et al. (1980) and Baldyga and Bourne (1983) and 8 compared with the experimental data from Nunes et al. (2012). The data from the striation 9 thickness models was compared to the deformation undergone by material elements in CIJ mixers obtained from CFD simulations and using particle tracking approaches.

Results from the LM model show that the striation thickness function proposed by Lee et al. (1980) gives the best estimation of the striation thickness evolution for a range of Reynolds number $200<\mathrm{Re}<600$. The description of the micromixing from the LM model and the respective validation enable the use of the LM model as a design tool for reactors based on CIJs technology.

3D CFD simulations show a nearly exponential increase of the average stretching of fluid elements with time for $\operatorname{Re}>110$, which is a feature of chaotic flows. These results indicate that smaller striation thicknesses of the liquid streams injected in the mixing chamber are observed with the increasing of Reynolds numbers. The striation thickness reduction obtained from CFD simulations is in agreement with the model of Lee et al. (1980).

The model proposed by Lee et al. (1980) is based on the balance of mechanical energy in the CIJ mixing chamber, and assumes that all energy injected in the mixing chamber is used in the generation of interfacial area between fluids. The validation of Lee et al. (1980) assumption from micromixing data, clearly shows that CIJs make a very efficient transfer of the jets kinetic energy into mixing.

These conclusions also present the definite proof that the flow in the studied range of Reynolds numbers for CIJs mixers is laminar. The mechanism of mixing in CIJs is the stretching of the interface between the two fluids as described in chaotic mixing for laminar flows.

\section{Acknowledgments}

This work was financially supported by: Associate Laboratory LSRE-LCM UID/EQU/50020/2019 - funded by national funds through FCT/MCTES (PIDDAC) and by POCI-01-0145-FEDER-016851 - funded by FEDER funds - Programa Operacional Competitividade e Internacionalização (POCI) - and by national funds through FCT - Fundação para a Ciência e a Tecnologia I.P.; M.S.C.A. Brito acknowledges her FCT scholarship $\mathrm{PD} / \mathrm{BD} / 135060 / 2017$.

\section{Notation}

$8 a$-maximum amplitude of the perturbation

$39 \quad A_{1}-1$-naphtol

$A_{1}-$ molar fraction of $\mathrm{A}_{1}$

$1 \quad A_{2}-2$-naphtol

$A_{2}$ - molar fraction of $\mathrm{A}_{2}$ 
$1 \quad b$ - time relative to chamber mean residence time over which perturbation is applied [s]

2 B - diazotized sulfanilic acid

$3 \quad B-$ molar fraction of $B$

$4 \quad C_{i}$ - concentration of species $i\left[\mathrm{~mol} \mathrm{~m}^{-3}\right]$

$5 \quad C_{i}^{\text {feed }}-$ feed concentration of species $i\left[\mathrm{~mol} \mathrm{~m}^{-3}\right]$

$6 C_{i}, 0-$ initial concentration of species $i\left[\mathrm{~mol} \mathrm{~m}^{-3}\right]$

7 C - Right Cauchy-Green deformation tensor

$8 \quad d$ - injectors diameter $[\mathrm{m}]$

$9 \mathrm{~d} R$ - initial distance between two elements [m]

$10 \mathrm{~d} r$ - distance between two elements [m]

$11 \mathrm{~d} X_{1}-$ initial coordinate of two elements

$12 \mathrm{~d} X_{2}-$ initial coordinate of two elements

$13 \mathrm{~d} X_{3}-$ initial coordinate of two elements

$14 \mathrm{~d} x_{1}$ - coordinate of two elements

$15 \mathrm{~d} x_{2}$ - coordinate of two elements

$16 \mathrm{~d} x_{3}$ - coordinate of two elements

$17 D$ - mixing chamber diameter $[\mathrm{m}]$

$18 D_{i}-$ diffusivity coefficient of species $i\left[\mathrm{~m}^{2} \mathrm{~s}^{-1}\right]$

19 D - stretching tensor $\left[\mathrm{s}^{-1}\right]$

20 Da - Damkoler number

$21 D_{m}-$ molecular diffusion coefficient $\left[\mathrm{m}^{2} \mathrm{~s}^{-1}\right]$

$22 E$ - proportional factor in the equation $s_{0}=E d$

$23 \quad \mathbf{F}$ - deformation gradient tensor

$24 f$-perturbation time function

$25 h$-headspace of the mixing chamber [m]

$26 \quad H$ - mixing chamber height $[\mathrm{m}]$

$27 \mathrm{H}-$ Heaviside function

28 I - Identity tensor

$29 k_{1}$ - rate constant of the reaction $\mathrm{A}_{1}+\mathrm{B} \stackrel{k_{1}}{\rightarrow} \mathrm{R}\left[\mathrm{m}^{3} \mathrm{~mol}^{-1} \mathrm{~s}^{-1}\right]$

$30 k_{2}$-rate constant of the reaction $\mathrm{R}+\mathrm{B} \stackrel{k_{2}}{\rightarrow} \mathrm{S}\left[\mathrm{m}^{3} \mathrm{~mol}^{-1} \mathrm{~s}^{-1}\right]$

$31 k_{3}-$ rate constant of the reaction $\mathrm{A}_{2}+\mathrm{B} \stackrel{k_{3}}{\rightarrow} \mathrm{Q}\left[\mathrm{m}^{3} \mathrm{~mol}^{-1} \mathrm{~s}^{-1}\right]$ 
$1 \quad \mathbf{M}$ - parameter which defines the symmetry of the problem

$2 n$-the number of mixing head diameters

$3 \mathbf{n}$ - normal unitary vector

$4 \quad n_{t}$ - time discretization

$5 \quad n_{x}$-spatial discretization

$6 \quad N_{\text {particles }}-$ number of injected particles

$7 \quad p$ - pressure $[\mathrm{Pa}]$

$8 \quad p_{0}$-initial pressure $[\mathrm{Pa}]$

$9 \quad \mathrm{Q}$-2,4-bis[(4'-sulfophenyl)azo]-2-naphtol

$10 Q-$ molar fraction of $Q$

$11 r_{s}$ - flow rate ratio

$12 \mathrm{R}$ - generic reaction product product or $\mathrm{R}=\mathrm{o}-\mathrm{R}+\mathrm{p}-\mathrm{R}$ where $\mathrm{o}-\mathrm{R}$ is $2-\left[\left(4^{\prime}\right.\right.$-sulfophenyl)azo $]-1$ -

13 naphtol and $\mathrm{p}-\mathrm{R}$ is 4-[(4'-sulfophenyl)azo]-1-naphtol

$14 R$ - molar fraction of $\mathrm{R}$

15 Re - Reynolds Number

$16 \quad R_{i}$ - reaction expression $\left[\mathrm{mol} \mathrm{m}^{-3} \mathrm{~s}^{-1}\right]$

$17 s$ - striation thickness $[\mathrm{m}]$

$18 s_{0}-$ initial striation thickness [m]

19 S-2,4-bis[(4'-sulfophenyl)azo]-1-naphtol

$20 S$ - molar fraction of S

$21 t$ - time $[\mathrm{s}]$

$22 t_{D}-$ characteristic diffusion time $[\mathrm{s}]$

$23 \quad t_{\text {micromixing }}-$ micromixing time $[\mathrm{s}]$

$24 t_{R}$-reaction time [s]

$25 \quad T$ - temperature $[\mathrm{K}]$

26

$\mathbf{u}-$ velocity vector $\left[\mathrm{m} \mathrm{s}^{-1}\right]$

$27 x$-Cartesian coordinate and position vector $[\mathrm{m}]$

$28 \mathbf{x}$ - position vector $[\mathrm{m}]$

$29 \mathbf{X}$ - initial position vector $[\mathrm{m}]$

$30 \quad X_{i}$ - selectivity of species $i$

$31 \Delta x-$ space scale of micromixing $[\mathrm{m}]$

32 $y$-Cartesian coordinate 
$3 \alpha$ - name of the particle

$4 \alpha(\mathbf{X}, t)$ - rate of expansion or contraction around particle $\mathbf{X}\left[\mathrm{s}^{-1}\right]$

$5 \quad \beta$ - name of the particle

$6 \quad \beta_{1}$ - ratio between the initial concentrations of $A_{1}$ and $B$

$7 \beta_{2}$-ratio between the initial concentrations of $A_{2}$ and $B$

$8 \gamma_{\mathrm{A}_{1}}$ - stoichiometric ratio between the initial concentration of $\mathrm{A}_{1}$ and $\mathrm{B}$

$9 \quad \gamma_{\mathrm{A}_{2}}$ - stoichiometric ratio between the initial concentration of $\mathrm{A}_{2}$ and $\mathrm{A}_{1}$

$10 \dot{\gamma}_{\text {injector }}$ strain rate of fluid at the injector's wall $\left[\mathrm{s}^{-1}\right]$

$11 \Gamma$-time

$12 \varepsilon$ - the energy dissipation rate per unit mass [W $\left.\mathrm{kg}^{-1}\right]$

$13 \varepsilon_{1}$ - ratio between $k_{2}$ and $k_{1}$

$14 \quad \varepsilon_{2}$-ratio between $k_{3}$ and $k_{1}$

$15 \zeta$ - Non-dimensional rate of strain

$\eta$ - ratio between the initial striation thickness and the striation thickness

$17 \theta$-dimensionless time

$\lambda-$ stretching function

$\lambda_{K}-$ Kolmogorov scale $[\mathrm{m}]$

$\mu$ - fluid viscosity [Pa·s]

$v$ - kinematic viscosity $\left[\mathrm{m}^{2} \mathrm{~s}^{-1}\right]$

$\xi$ - position coordinate

$\rho$ - density $\left[\mathrm{kg} \mathrm{m}^{-3}\right]$

$\tau$ - residence time $[\mathrm{s}]$

$v_{\text {inj }}$ - velocity at the injector $\left[\mathrm{m} \mathrm{s}^{-1}\right]$

\section{References}

27 Andreussi, T., Galletti, C., Mauri, R., Camarri, S., Salvetti, M.V., 2015. Flow regimes in T-shaped micro-mixers. Computers and Chemical Engineering 76, 150-159.

29 Baldyga, J., Bourne, J., 1999. Turbulent Mixing and Chemical Reactions. John Willey 30 \& Sons Ltd, New York.

31 Baldyga, J., Bourne, J.R., 1983. Distribution of striation thickness from impingement 32 mixers in reaction injection molding. Polymer Engineering \& Science 23, 556-559.

33 Bothe, D., Lojewski, A., Warnecke, H.J., 2010. Computational analysis of an 34 instantaneous chemical reaction in a T-microreactor. AIChE Journal 56, 1406-1415. 
Bothe, D., Lojewski, A., Warnecke, H.J., 2011. Fully resolved numerical simulation of reactive mixing in a $\mathrm{T}$-shaped micromixer using parabolized species equations.

Chemical Engineering Science 66, 6424-6440.

Bothe, D., Stemich, C., Warnecke, H.J., 2006. Fluid mixing in a T-shaped micro-mixer. Chemical Engineering Science 61, 2950-2958.

Bothe, D., Stemich, C., Warnecke, H.J., 2008. Computation of scales and quality of mixing in a T-shaped microreactor. Computers and Chemical Engineering 32, 108-114. Bourne, J.R., Hilber, C., Tovstiga, G., 1985. Kinetics of the Azo Coupling Reactions Between 1-Naphthol And Diazotised Sulphanilic Acid. Chemical Engineering Communications 37, 293-314.

Bourne, J.R., Kut, O.M., Lenzner, J., Maire, H., 1990. Kinetics of the diazo coupling between 1-naphthol and diazotized sulfanilic acid. Industrial \& Engineering Chemistry Research 29, 1761-1765.

Delgado, J.M.P.Q., Guedes de Carvalho, J.R.F., 2001. Measurement of the Coefficient of Transverse Dispersion in Flow Through Packed Beds for a Wide Range of Values of the Schmidt Number. Transport in Porous Media 44, 165-180.

Dreher, S., Kockmann, N., Woias, P., 2009. Characterization of laminar transient flow regimes and mixing in t-shaped micromixers. Heat Transfer Engineering 30, 91-100. Engler, M., Kockmann, N., Kiefer, T., Woias, P., 2004. Numerical and experimental investigations on liquid mixing in static micromixers. Chemical Engineering Journal 101, 315-322.

Erkoç, E., Santos, R.J., Nunes, M.I., Dias, M.M., Lopes, J.C.B., 2007. Mixing dynamics control in RIM machines. Chemical Engineering Science 62, 5276-5281.

Fani, A., Camarri, S., Salvetti, M.V., 2013. Investigation of the steady engulfment regime in a three-dimensional T-mixer. Physics of Fluids 25.

Feng, H., Olsen, M.G., Liu, Y., Fox, R.O., Hill, J.C., 2005. Investigation of turbulent mixing in a confined planar-jet reactor. AIChE Journal 51, 2649-2664.

Fonte, C.P., Sultan, M.A., Santos, R.J., Dias, M.M., Lopes, J.C.B., 2015. Flow imbalance and Reynolds number impact on mixing in Confined Impinging Jets. Chemical Engineering Journal 260, 316-330.

Fonte, C.P., Sultan, M.A., Santos, R.J., Dias, M.M., Lopes, J.C.B., 2016. An elastic analog model for controlling the impingement point position in confined impinging jets. AIChE Journal 62, 2200-2212.

Galletti, C., Roudgar, M., Brunazzi, E., Mauri, R., 2012. Effect of inlet conditions on the engulfment pattern in a T-shaped micro-mixer. Chemical Engineering Journal 185186, 300-313.

Gavi, E., Marchisio, D.L., Barresi, A.A., 2007a. CFD modelling and scale-up of Confined Impinging Jet Reactors. Chemical Engineering Science 62, 2228-2241. Gavi, E., Rivautella, L., Marchisio, D.L., Vanni, M., Barresi, A.A., Baldi, G., 2007b. CFD modelling of nano-particle precipitation in confined impinging jet reactors. Chemical Engineering Research and Design 85, 735-744.

Gholap, R.V., Petrozzi, S., Bourne, J.R., 1994. Influence of viscosity on product distribution of fast competitive chemical reactions. Chemical Engineering \& Technology 17, 102-107.

Gobby, D., Angeli, P., Gavriilidis, A., 2001. Mixing chacteristics of T-type microfluidic mixers. Journal of Micromechanics and Microengineering 11, 126-132.

Gomes, N.M.O., Fonte, C.P., Sousa, C.C.E., Mateus, A.J., Bártolo, P.J., Dias, M.M., Lopes, J.C.B., Santos, R.J., 2016. Real time control of mixing in Reaction Injection Moulding. Chemical Engineering Research and Design 105, 31-43. 
Gonçalves, N.D., Salvador, H.M., Fonte, C.P., Dias, M.M., Lopes, J.C.B., Santos, R.J., 2017. On the 2D nature of flow dynamics in opposed jets mixers. AIChE Journal 63, 2335-2347.

Gradl, J., Peukert, W., 2009. Simultaneous 3D observation of different kinetic subprocesses for precipitation in a T-mixer. Chemical Engineering Science 64, 709-720. Gradl, J., Schwarzer, H.-C., Schwertfirm, F., Manhart, M., Peukert, W., 2006. Precipitation of nanoparticles in a T-mixer: Coupling the particle population dynamics with hydrodynamics through direct numerical simulation. Chemical Engineering and Processing: Process Intensification 45, 908-916.

Hoffmann, M., Schlüter, M., Räbiger, N., 2006. Experimental investigation of liquidliquid mixing in T-shaped micro-mixers using $\mu$-LIF and $\mu$-PIV. Chemical Engineering Science 61, 2968-2976.

Icardi, M., Gavi, E., Marchisio, D.L., Barresi, A.A., Olsen, M.G., Fox, R.O., Lakehal, D., 2011a. Investigation of the flow field in a three-dimensional Confined Impinging Jets Reactor by means of microPIV and DNS. Chemical Engineering Journal 166, 294305.

Icardi, M., Gavi, E., Marchisio, D.L., Olsen, M.G., Fox, R.O., Lakehal, D., 2011 b. Validation of LES predictions for turbulent flow in a Confined Impinging Jets Reactor. Applied Mathematical Modelling 35, 1591-1602.

Johnson, D.A., 2000a. Experimental and numerical examination of confined laminar opposed jets Part II. Momentum balancing. International Communications in Heat and Mass Transfer 27, 455-463.

Johnson, D.A., 2000b. Experimental and Numerical Examination of Confined Laminar Opposed Jets. Part I Momentum Imbalance. International Communications in Heat and Mass Transfer 27, 443-454.

Johnson, D.A., Wood, P., Hrymak, A.N., 1996. The Effect of Geometrical Parameters on the Flow Field of an Opposed Jet RIM Mix Head: Equal Flow and Matched Fluids. Canadian Journal of Chemical Engineering 74, 40-48.

Keuerleber, R., Pahl, F., 1970. Device for feeding flowable material to a mold cavity, in: USPT (Ed.).

Kolodziej, P., Macosko, C.W., Ranz, W.E., 1982. The influence of impingement mixing on striation thickness distribution and properties in fast polyurethane polymerization. Polymer Engineering \& Science 22, 388-392.

Kolodziej, P., Yang, W.P., Macosko, C.W., Wellinghoff, S.T., 1986. Impingement mixing and its effect on the microstructure of RIM polyurethanes. Journal of Polymer Science Part B: Polymer Physics 24, 2359-2377.

Krupa, K., Nunes, M.I., Santos, R.J., Bourne, J.R., 2014. Characterization of micromixing in T-jet mixers. Chemical Engineering Science 111, 48-55. Krupa, K., Sultan, M.A., Fonte, C.P., Nunes, M.I., Dias, M.M., Lopes, J.C.B., Santos, R.J., 2012. Characterization of mixing in T-jets mixers. Chemical Engineering Journal 207-208, 931-937.

Kusch, H.A., Ottino, J.M., Shannon, D.M., 1989. Analysis of impingement mixingreaction data: use of a lamellar model to generate fluid mixing information. Industial \& Chemical Engineering Research 28, 302-315.

Lee, L.J., Ottino, J.M., Ranz, W.E., Macosko, C.W., 1980. Impingement mixing in reaction injection molding. Polymer Engineering \& Science 20, 868-874.

Li, W.F., Qian, W.W., Yu, G.S., Liu, H.F., Wang, F.C., 2015. Experimental study of oscillation behaviors in confined impinging jets reactor under excitation. AIChE Journal 61, 333-341. 
Li, W.F., Wei, Y., Tu, G.Y., Shi, Z.H., Liu, H.F., Wang, F.C., 2016. Experimental study about mixing characteristic and enhancement of T-jet reactor. Chemical Engineering Science 144, 116-125.

Lince, F., Marchisio, D.L., Barresi, A.A., 2009. Smart mixers and reactors for the production of pharmaceutical nanoparticles: Proof of concept. Chemical Engineering Research and Design 87, 543-549.

Liu, Y., Fox, R.O., 2006. CFD predictions for chemical processing in a confined impinging-jets reactor. AIChE Journal 52, 731-744.

Liu, Y., Olsen, M.G., Fox, R.O., 2009. Turbulence in a microscale planar confined impinging-jets reactor. Lab on a Chip 9, 1110-1118.

Malguarnera, S.C., Suh, N.P., 1977. Liquid injection molding I. An investigation of impingement mixing. Polymer Engineering \& Science 17, 111-115.

Mariotti, A., Galletti, C., Mauri, R., Salvetti, M.V., Brunazzi, E., 2018. Steady and unsteady regimes in a T-shaped micro-mixer: Synergic experimental and numerical investigation. Chemical Engineering Journal 341, 414-431.

Mariotti, A., Galletti, C., Salvetti, M.V., Brunazzi, E., 2019. Unsteady Flow Regimes in a T-Shaped Micromixer: Mixing and Characteristic Frequencies. Industrial \& Engineering Chemistry Research 58, 13340-13356.

Nakamura, S., Brodkey, R.S., 2000. Direct and Large Eddy Simulation of the ThreeDimensional Unsteady Flows in the Counter-Jet Mixing Vessel, ASME Fluids Engineering Summer Conference, Boston, Massachusetts.

Nunes, M.I., Santos, R.J., Dias, M.M., Lopes, J.C.B., 2012. Micromixing assessment of confined impinging jet mixers used in RIM. Chemical Engineering Science 74, 276286.

Orsi, G., Galletti, C., Brunazzi, E., Mauri, R., 2013a. Mixing of two miscible liquids in T-shaped microdevices. Chemical Engineering Transactions 32, 1471-1476.

Orsi, G., Roudgar, M., Brunazzi, E., Galletti, C., Mauri, R., 2013b. Water-ethanol mixing in T-shaped microdevices. Chemical Engineering Science 95, 174-183. Ottino, J.M., 1980. Lamellar Mixing Models for Structured Chemical Reactions and Their Relationship to Statistical Models; Macro-and Micromixing and the Problem of Averages. Chemical Engineering Science 35, 1377-1391.

Ottino, J.M., 1982. Description of mixing with diffusion and reaction in terms of the concept of material surfaces. Journal of Fluid Mechanics 114, 83-103.

Ottino, J.M., 1990. The Kinematics of Mixing: Stretching, Chaos and Transport. Cambridge University Press, Cambridge.

Ottino, J.M., Ranz, W.E., Macosko, C.W., 1979. A lamellar model for analysis of liquid-liquid mixing. Chemical Engineering Science 34, 877-890.

Ranz, W.E., 1979. Applications of a Stretch Model to Mixing Diffusion, and Reaction in Laminar and Turbulent Flows. AIChE Journal 25, 41-47.

Ranz, W.E., 1986. Analysis of Reaction Processes in Which Microscopic

Heterogeneities Appear: Scale-Up and Scale-Down of Polymerization Reactions. Industrial and Engineering Chemistry Fundamentals 25, 561-565.

Ritcher, E.B., Macosko, C.W., 1978. Kinetics of Fast (RIM) Urethane Polymerization. Polymer Engineering and Science 18.

Santos, R.J., 2003, Mixing Mechanisms in Reaction Injection Moulding - RIM. PhD Thesis of University of Porto Santos, R.J., Erkoç, E., Dias, M.M., Lopes, J.C.B., 2009. Dynamic behavior of the flow field in a RIM machine mixing chamber. AIChE Journal 55, 1338-1351. 
Santos, R.J., Erkoc, E., Dias, M.M., Teixeira, A.M., Lopes, J.C.B., 2008.

Hydrodynamics of the mixing chamber in RIM: PIV flow-field characterization. AIChE Journal 54, 1153-1163.

Santos, R.J., Sultan, M.A., 2013. State of the Art of Mini/Micro Jet Reactors. Chemical Engineering \& Technology 36, 937-949.

Santos, R.J., Teixeira, A.M., Costa, M.R.P.F.N., Lopes, J.C.B., 2002. Operational and design study of RIM machines. International Polymer Processing 17, 387-394.

Santos, R.J., Teixeira, A.M., Erkoç, E., Sultan, M., Karpinska, A.M., Dias, M.M., Lopes, J.C.B., 2010. Validation of a 2D CFD model for hydrodynamics' studies in CIJ mixers. International Journal of Chemical Reactor Engineering 8.

Schwarzer, H.C., Peukert, W., 2004. Combined experimental/numerical study on the precipitation of nanoparticles. AIChE Journal 50, 3234-3247.

Shi, Z.-h., Li, w.-f., Du, K.-j., Liu, H.-f., Wang, F.-c., 2015. Experimental study of mixing enhancement of viscous liquids in confined impinging jets reactor at low jet Reynolds numbers. Chemical Engineering Science 138, 216-226.

Siddiqui, S.W., Zhao, Y., Kukukova, A., Kresta, S.M., 2009. Characteristics of a confined impinging jet reactor: Energy dissipation, homogeneous and heterogeneous reaction products, and effect of unequal flow. Industrial and Engineering Chemistry Research 48, 7945-7958.

Soleymani, A., Kolehmainen, E., Turunen, I., 2007. Numerical and experimental investigations of liquid mixing in T-type micromixers. Chemical Engineering Journal 135, S219-S228.

Sultan, M.A., Fonte, C.P., Dias, M.M., Lopes, J.C.B., Santos, R.J., 2012. Experimental study of flow regime and mixing in T-jets mixers. Chemical Engineering Science 73, 388-399.

Sultan, M.A., Krupa, K., Fonte, C.P., Nunes, M.I., Dias, M.M., Lopes, J.C.B., Santos, R.J., 2013. High-Throughput T-Jets Mixers: An Innovative Scale-Up Concept. Chemical Engineering \& Technology 36, 323-331.

Teixeira, A.M., 2000, Escoamentos na Cabeça de Mistura de uma Máquina RIM. PhD Thesis of University of Porto

Telib, H., Manhart, M., Iollo, A., 2004. Analysis and low-order modeling of the inhomogeneous transitional flow inside a T-mixer. Physics of Fluids 16, 2717-2731. Thomas, S., Ameel, T.A., 2010. An experimental investigation of moderate reynolds number flow in a T-Channel. Experiments in Fluids 49, 1231-1245.

Tu, G., Li, W., Du, K., Huang, G., Wang, F., 2014a. Onset and influencing factors of deflecting oscillation in planar opposed jets. Chemical Engineering Journal 247, 125 133.

Tu, G.Y., Li, W.F., Du, K.J., Wang, F.C., 2014b. Experimental investigation of deflecting oscillation in T-jets reactor. Chemical Engineering Science 116, 734-744. Tucker, C.L., Suh, N.P., 1980. Mixing for reaction injection molding II. Impingement mixing of fiber suspensions. Polymer Engineering \& Science 20, 887-898.

Unger, D.R., Muzzio, F.J., Brodkey, R.S., 1998. Experimental and Numerical Characterization of Viscous Flow and Mixing in an Impinging Jet Contactor. The Canadian Journal of Chemical Engineering 76, 546-555.

Volpato, M., Fiorentini, C., 2012. Developments in Processing Equipment and Techniques, UTECH Europe 2012, Maastricht.

Wong, S.H., Ward, M.C.L., Wharton, C.W., 2004. Micro T-mixer as a rapid mixing micromixer. Sensors and Actuators, B: Chemical 100, 359-379. 
1 Wood, P., Hrymak, A., Yeo, R., Johnson, D., Tyagi, A., 1991. Experimental and

2 computational studies of the fluid mechanics in an opposed jet mixing head. Physics of 3 Fluids A 3, 1362-1368.

4 Zhao, Y., Brodkey, R.S., 1998. Averaged and Time-resolved Full-field (three-

5 dimensional), Measurements of Unsteady Opposed Jets. The Canadian Journal of

6 Chemical Engineering 76, 536-545. 
2 Figures

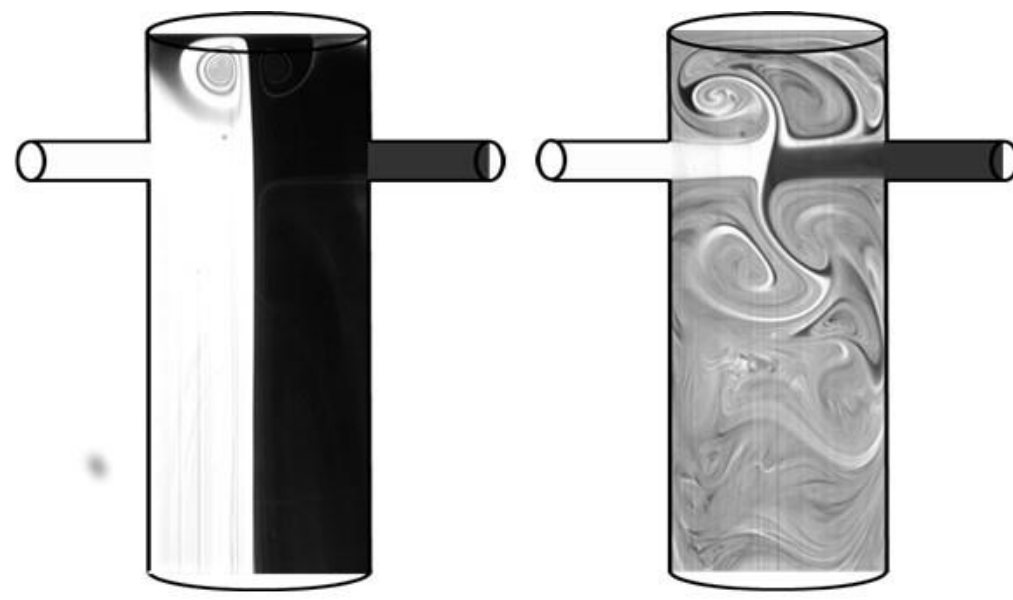

(a)

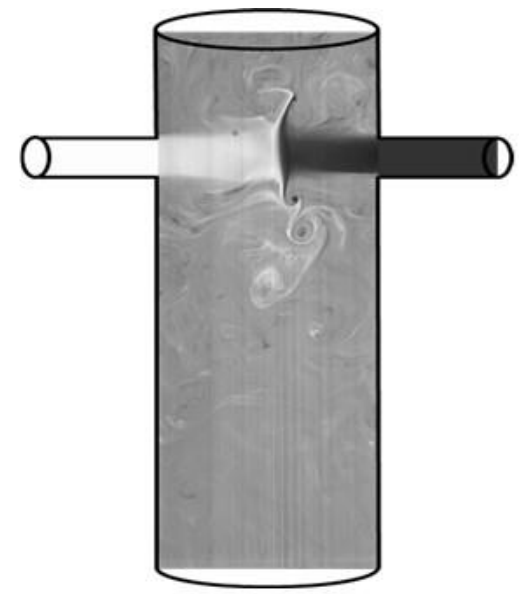

(c)

Figure 1 Sketch of CIJ mixing chamber framing PLIF images of concentration fields for (a) $R e=$ 103 , (b) $R e=111$ and (c) $R e=505$.

4 


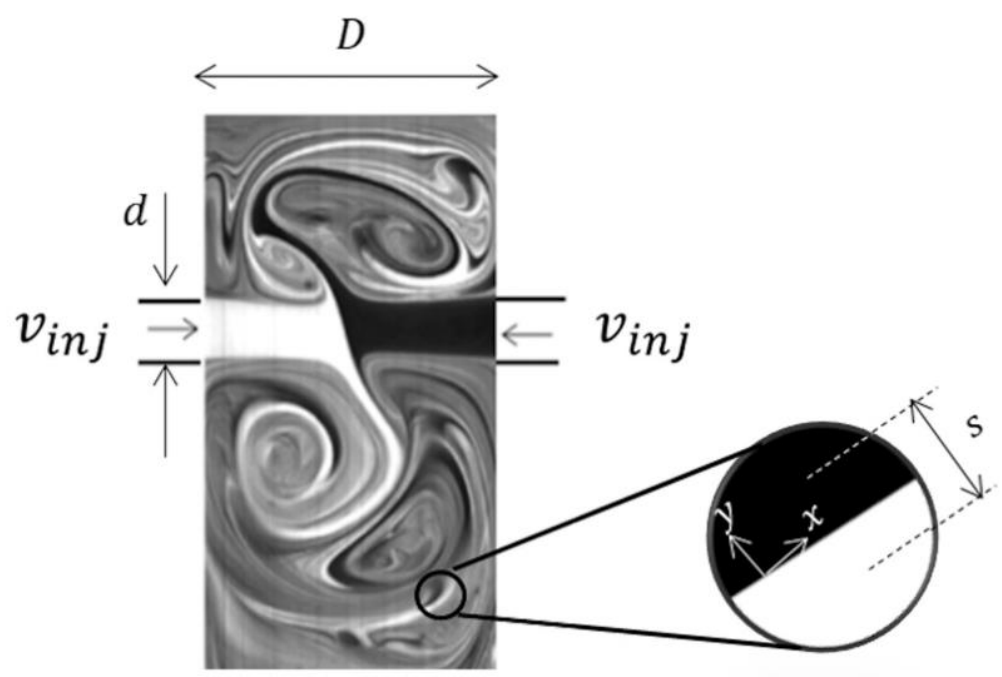

3

4 Figure 2 Lamellar Structure formed by impingement mixing in CIJs (PLIF data from 5 Fonte et al. (2015)) 


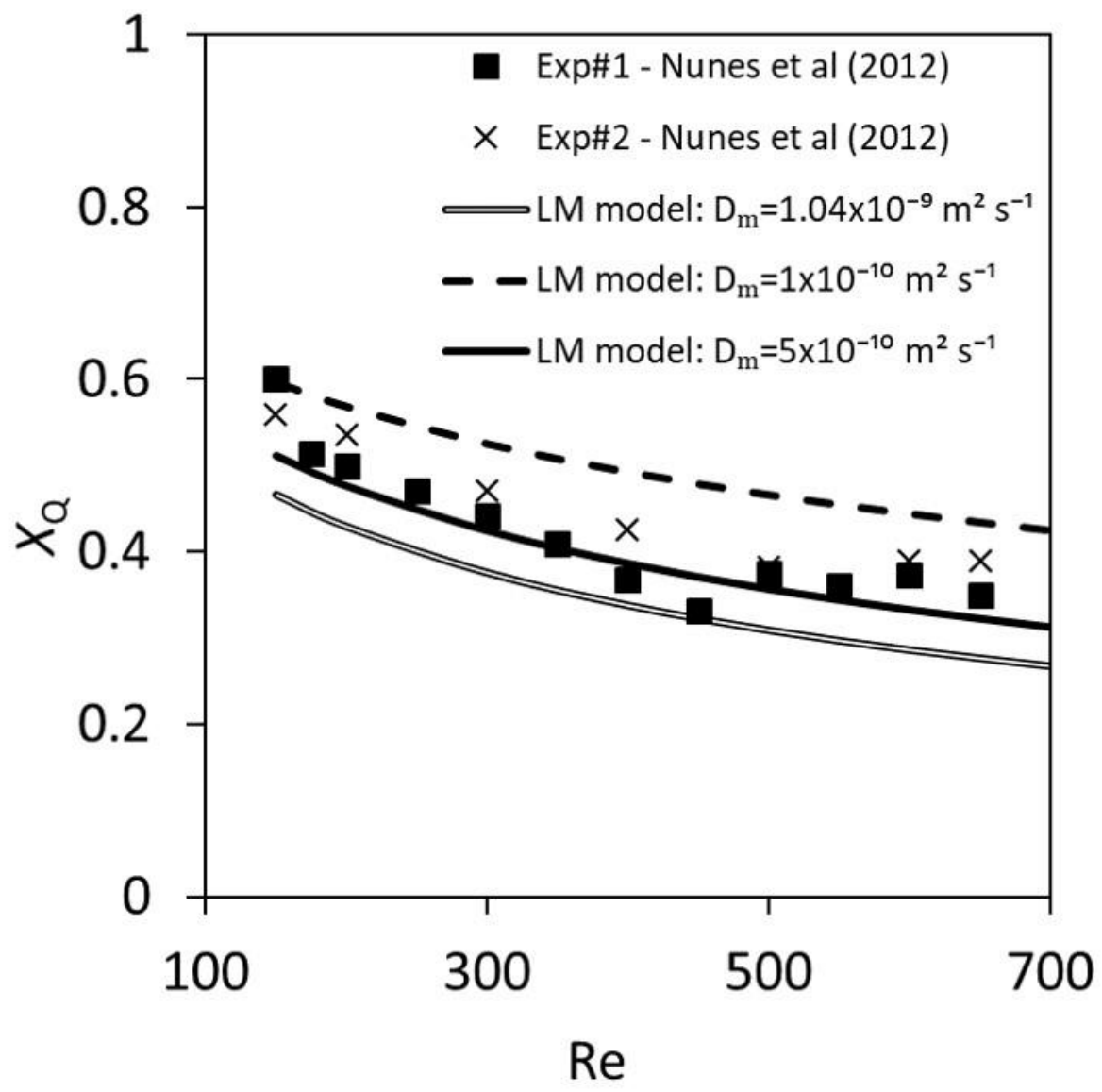

Figure 3 Product distribution obtained from experimental results (Nunes et al. 2012) and from LM model using the model defined by Lee et al. (1980) for the following experimental conditions: $C_{B, 0}=0.5 \mathrm{~mol} \mathrm{~m}{ }^{-3}, \gamma_{A_{1}}=1.1, t_{\text {reaction }} \sim 21 \mathrm{~ms}, \gamma_{A_{2}}=6$ and for a diffusional coefficient range between $D_{m}=1.04 \times 10^{-9}-1 \times$ $10^{-10} \mathrm{~m}^{2} \mathrm{~s}^{-1}$. 


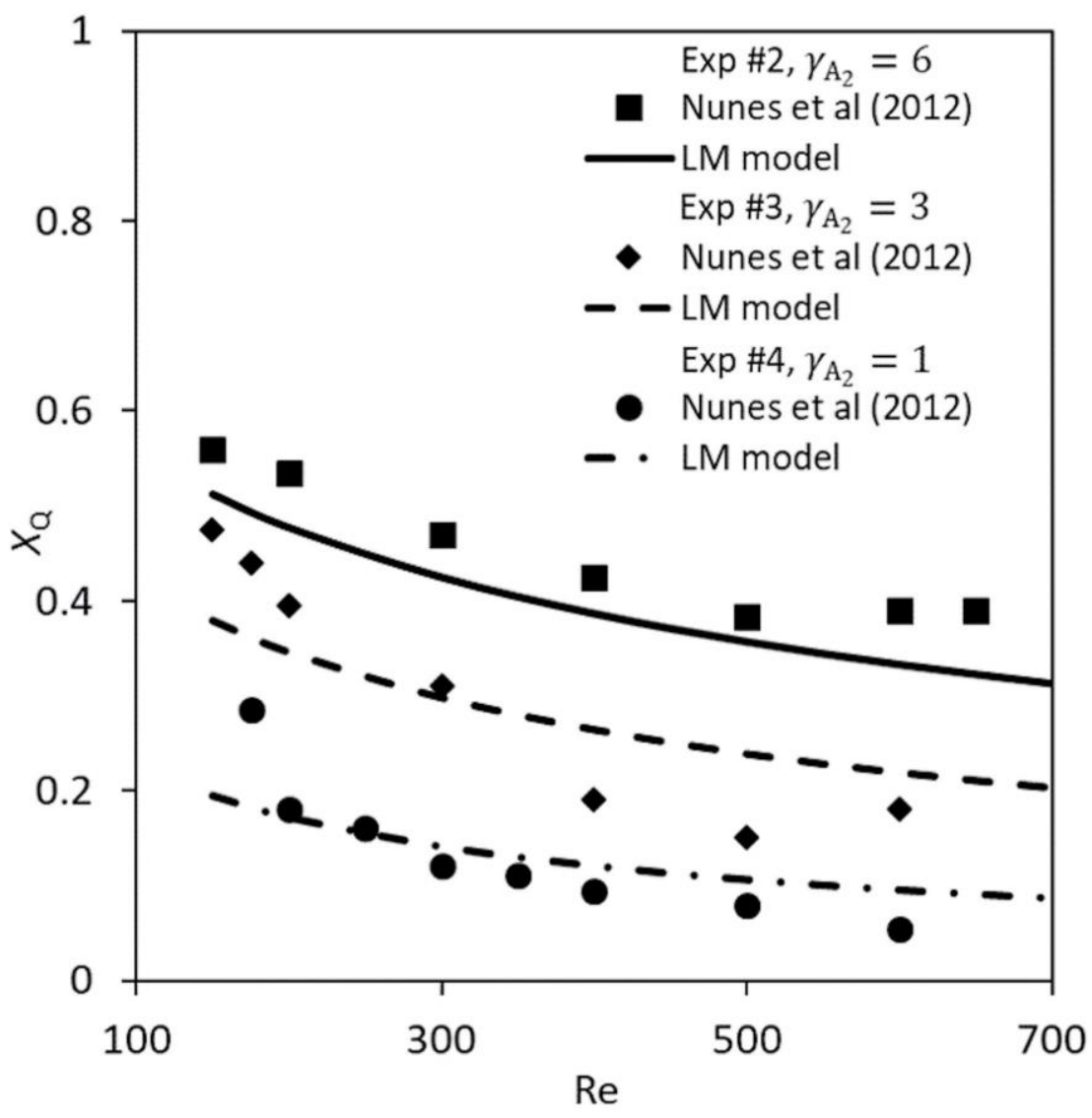

1

2 Figure 4 Product distribution obtained from experimental results (Nunes et al. 2012) and from LM model using the model defined by Lee et al. (1980) for the following experimental conditions: $C_{B, 0}=0.5 \mathrm{~mol} \mathrm{~m}{ }^{-3}, \gamma_{A_{1}}=1.1, t_{\text {reaction }} \sim 21 \mathrm{~ms}$ and different values of $\gamma_{A_{2}}$.

6 


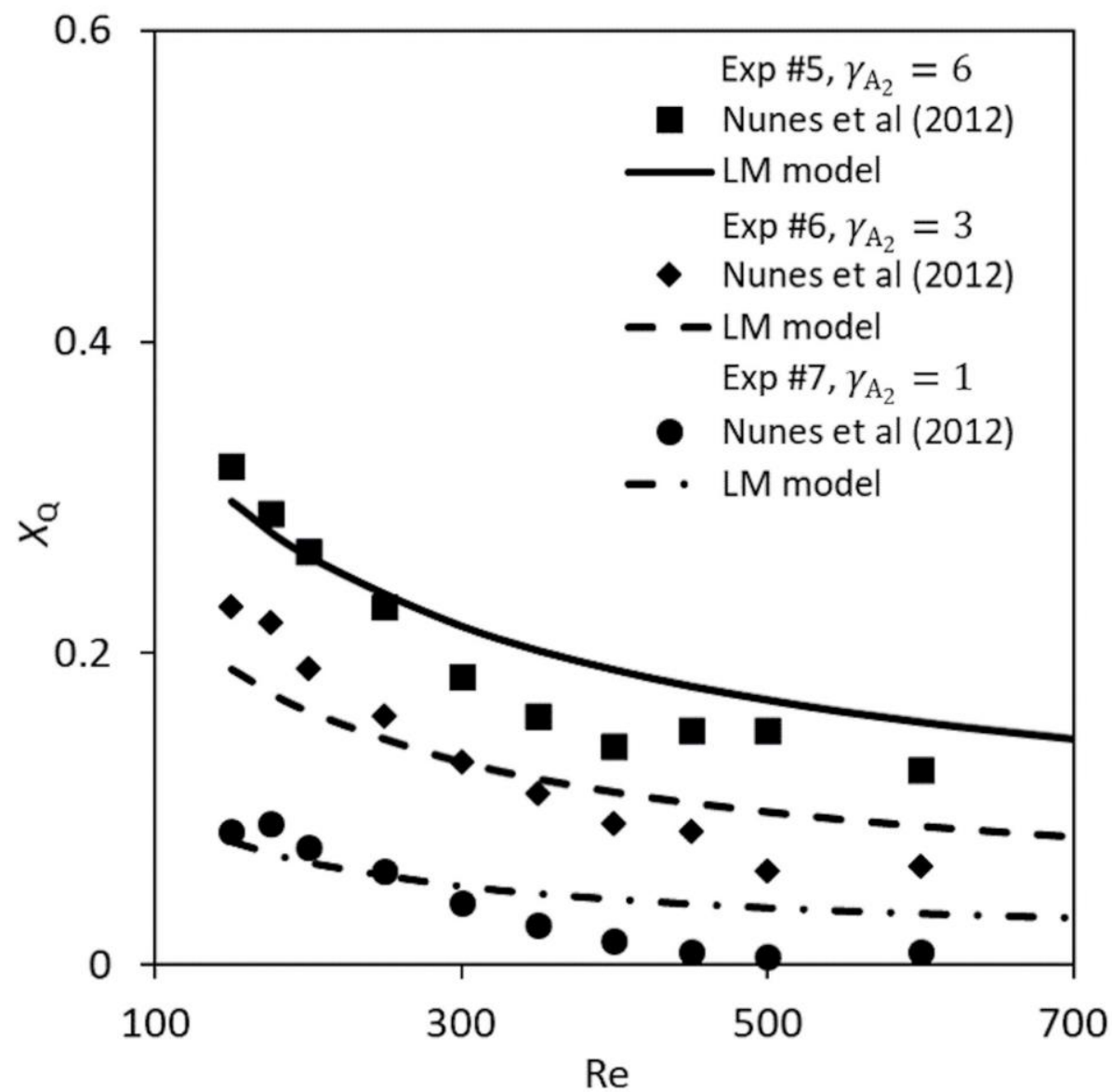

Figure 5 Product distribution obtained from experimental results (Nunes et al. 2012) and from LM model using the model defined by Lee et al. (1980) for the following experimental conditions: $C_{B, 0}=0.1 \mathrm{~mol} \mathrm{~m}{ }^{-3}, \gamma_{A_{1}}=1.2$, $t_{\text {reaction }} \sim 105 \mathrm{~ms}$ and different values of $\gamma_{A_{2}}$.

7

8

9 


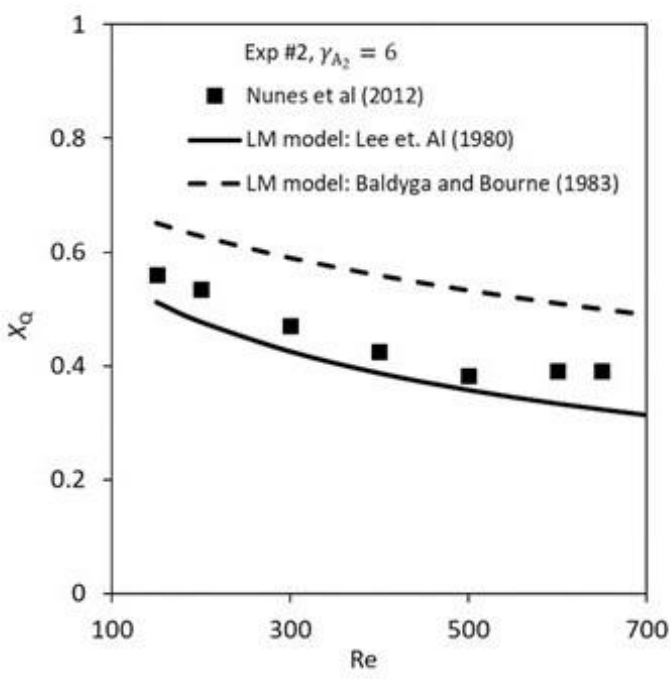

(a)

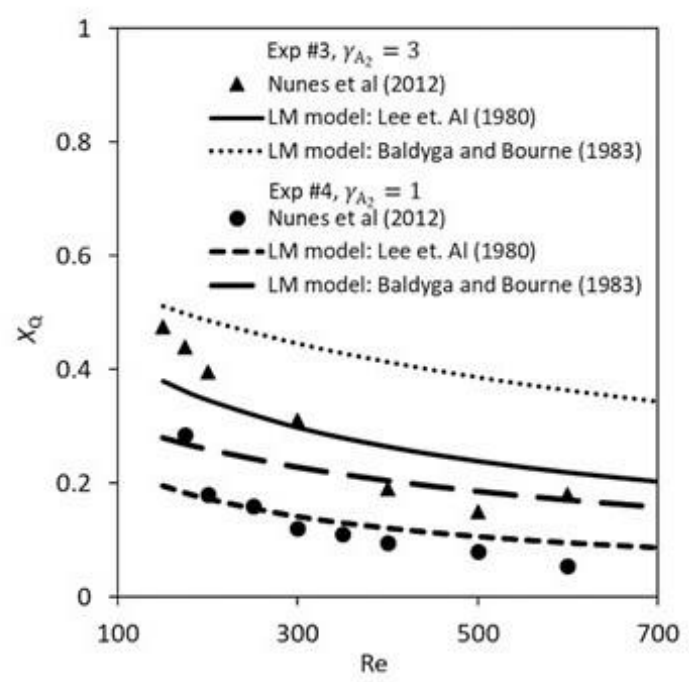

(b)

4 Figure 6 Product distribution obtained from experimental results (Nunes et al. 2012) and from LM model using the striation thickness reduction defined by Lee et al. (1980) and Baldyga and Bourne (1983): experiments 3 and 4. 


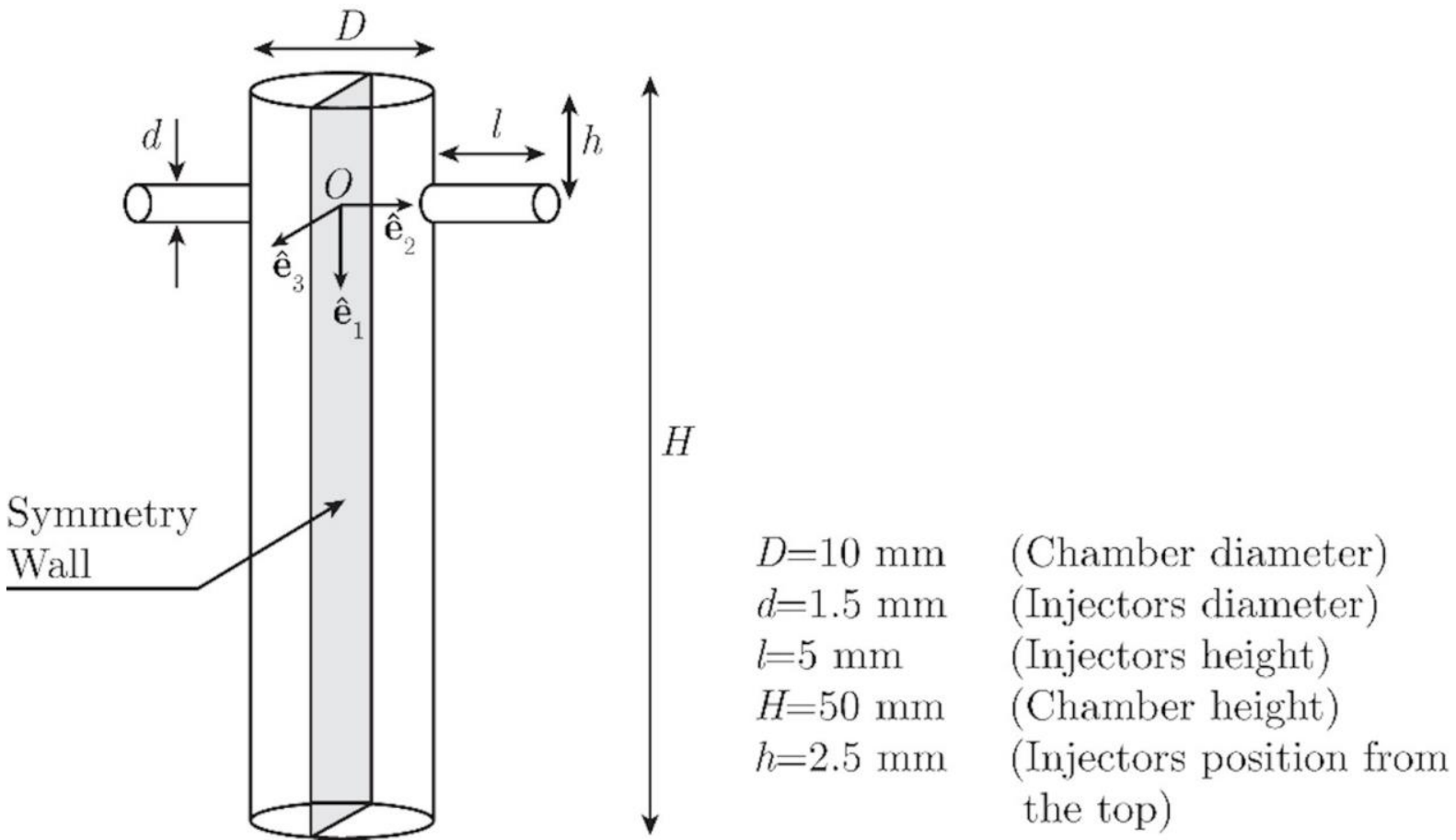

Figure 7 Schematic representation and dimensions of the simulation domain. 

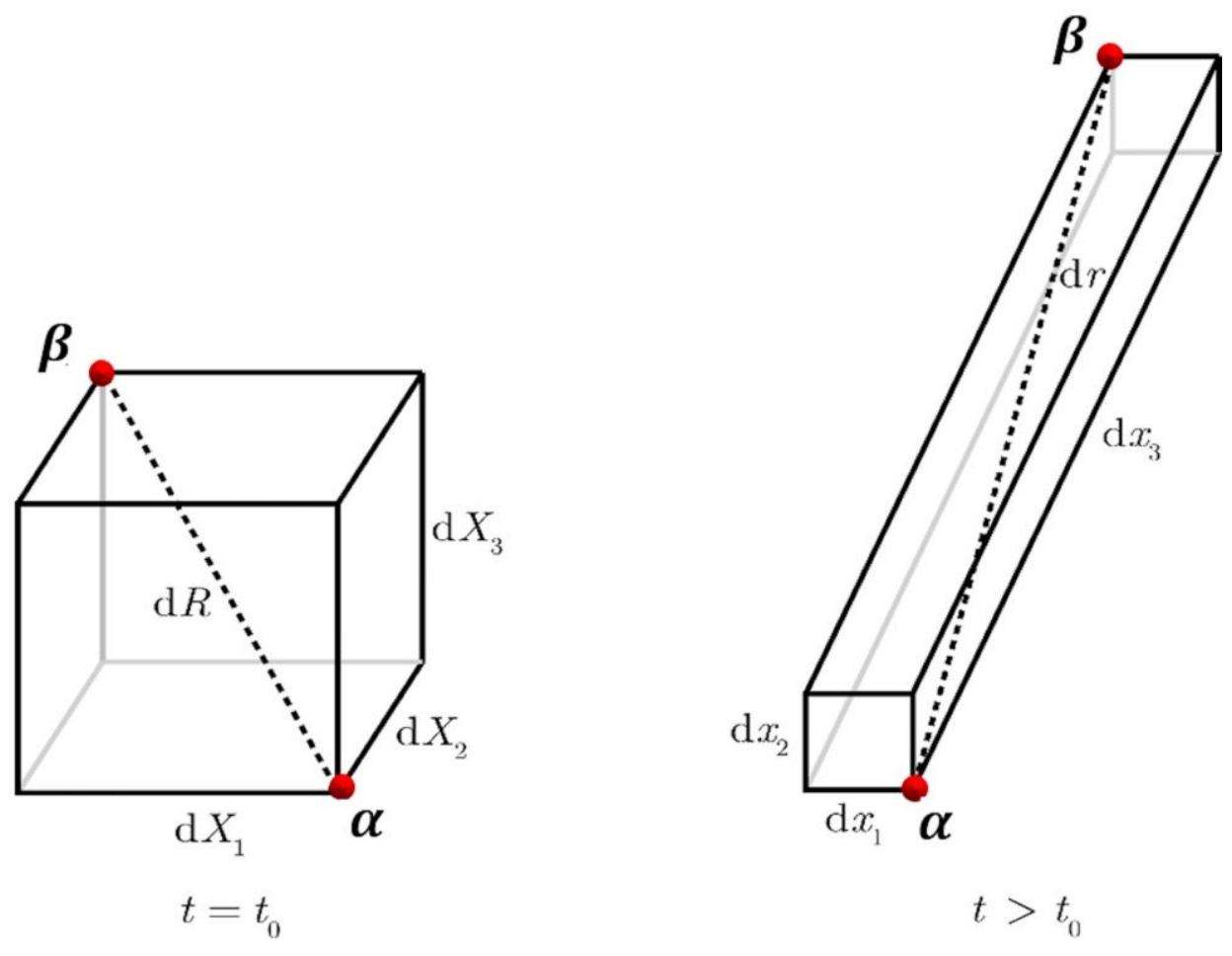

5 $t=t_{0}$

Figure 8 Separation of two particles ( $\alpha$ and $\beta$ ) in the flow as result of fluid deformation. 

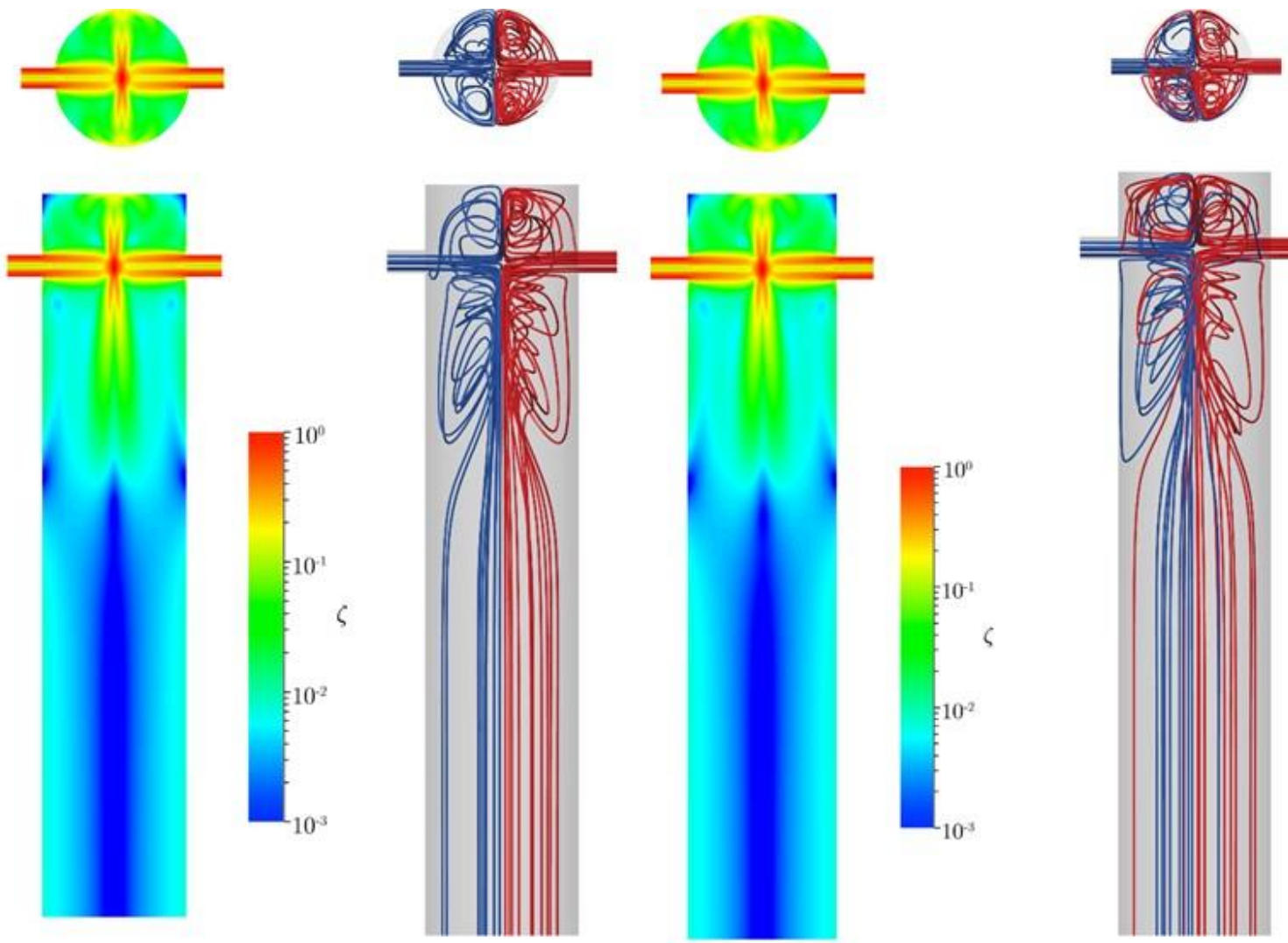

(a)
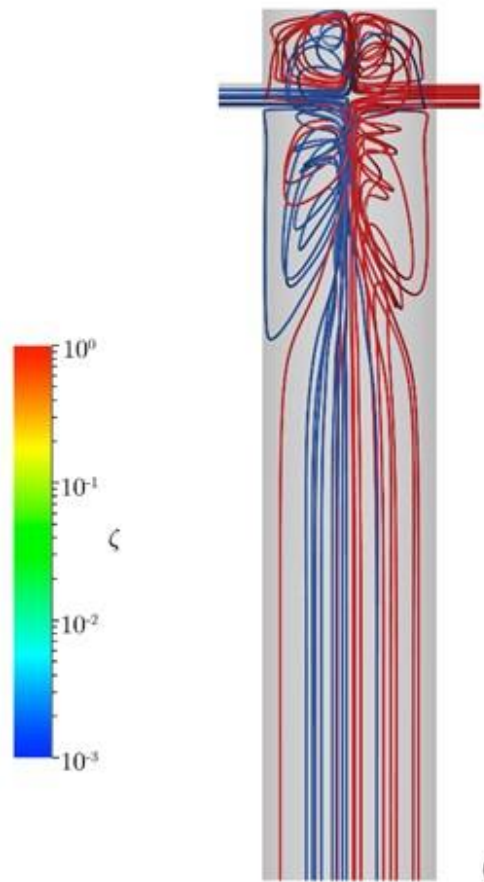

(b)

Figure 9 Top and side views of instantaneous non-dimensional strain rate field and of the streamlines for $R e=100:$ a) $t=0 \tau$ and b) $t=3 \tau$.

3

4

5 

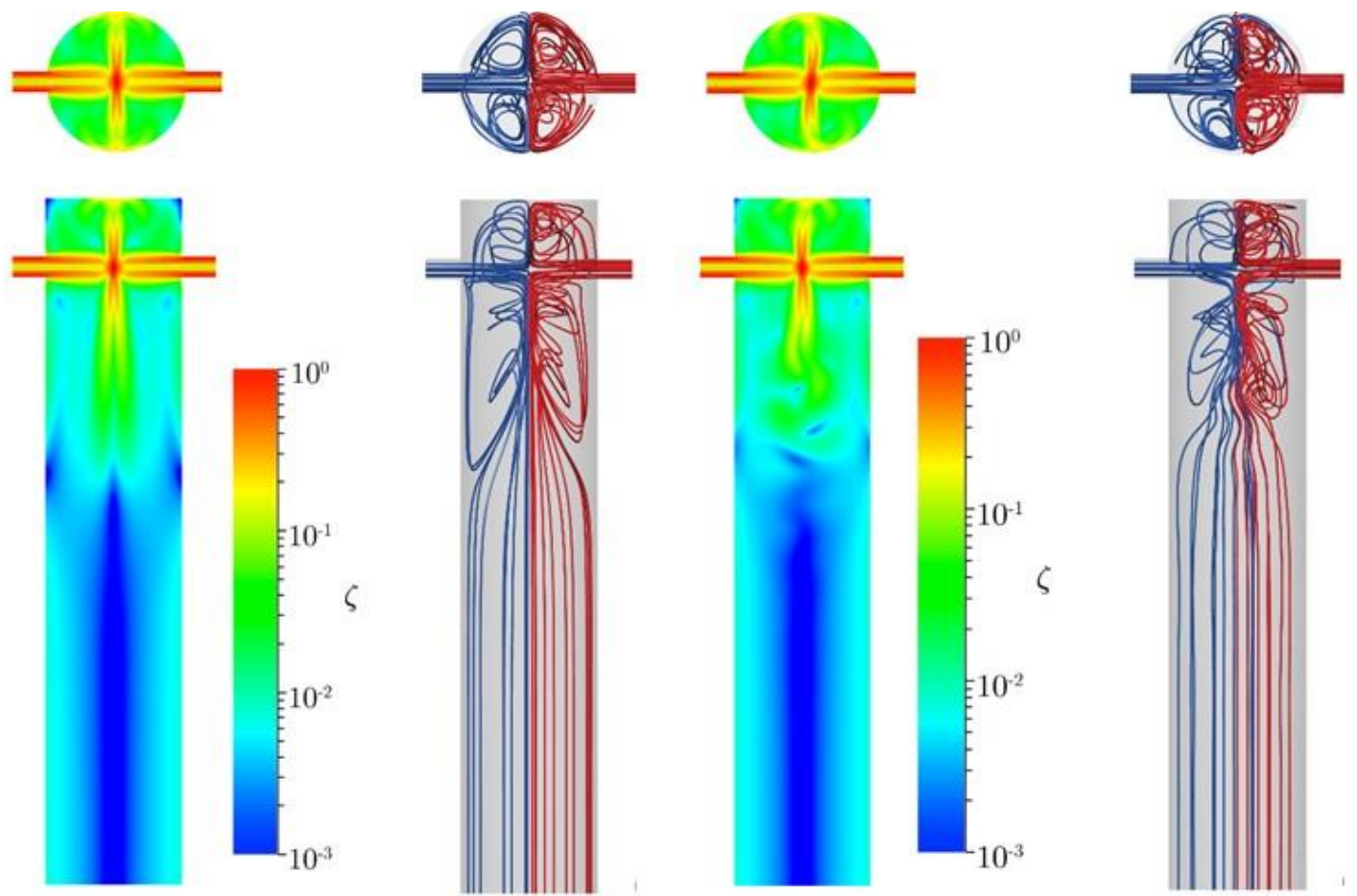

(b)

2 Figure 10 Top and side views of instantaneous non-dimensional strain rate field and of 3 the streamlines for $R e=110:$ a) $t=0 \tau$ and b) $t=3 \tau$.

4

5

6 

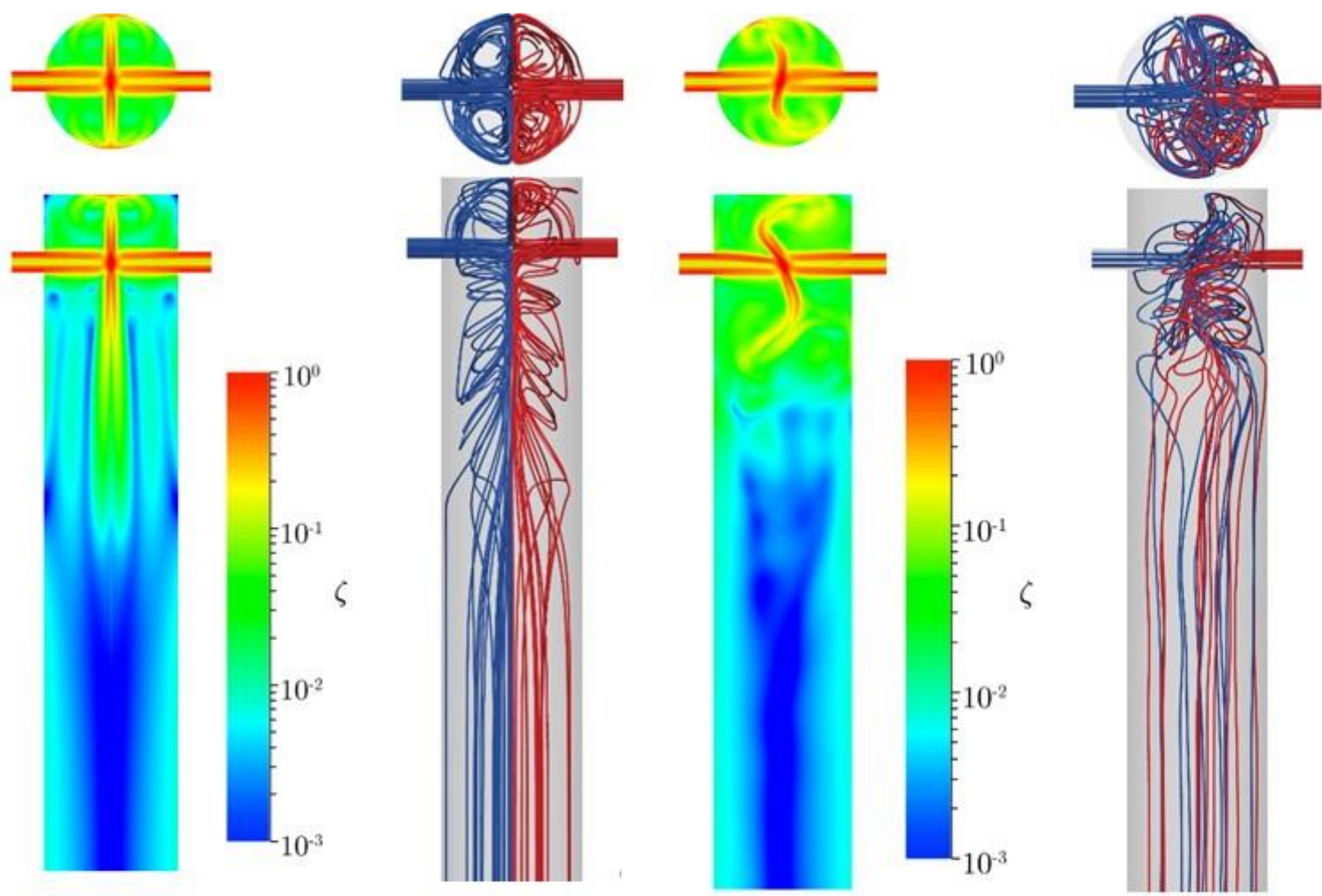

(a)

(b)

2

3

Figure 11 Top and side views of instantaneous non-dimensional strain rate field and of the streamlines for $R e=200$ : a) $t=0 \tau$ and b) $t=3 \tau$.

5

6

7 

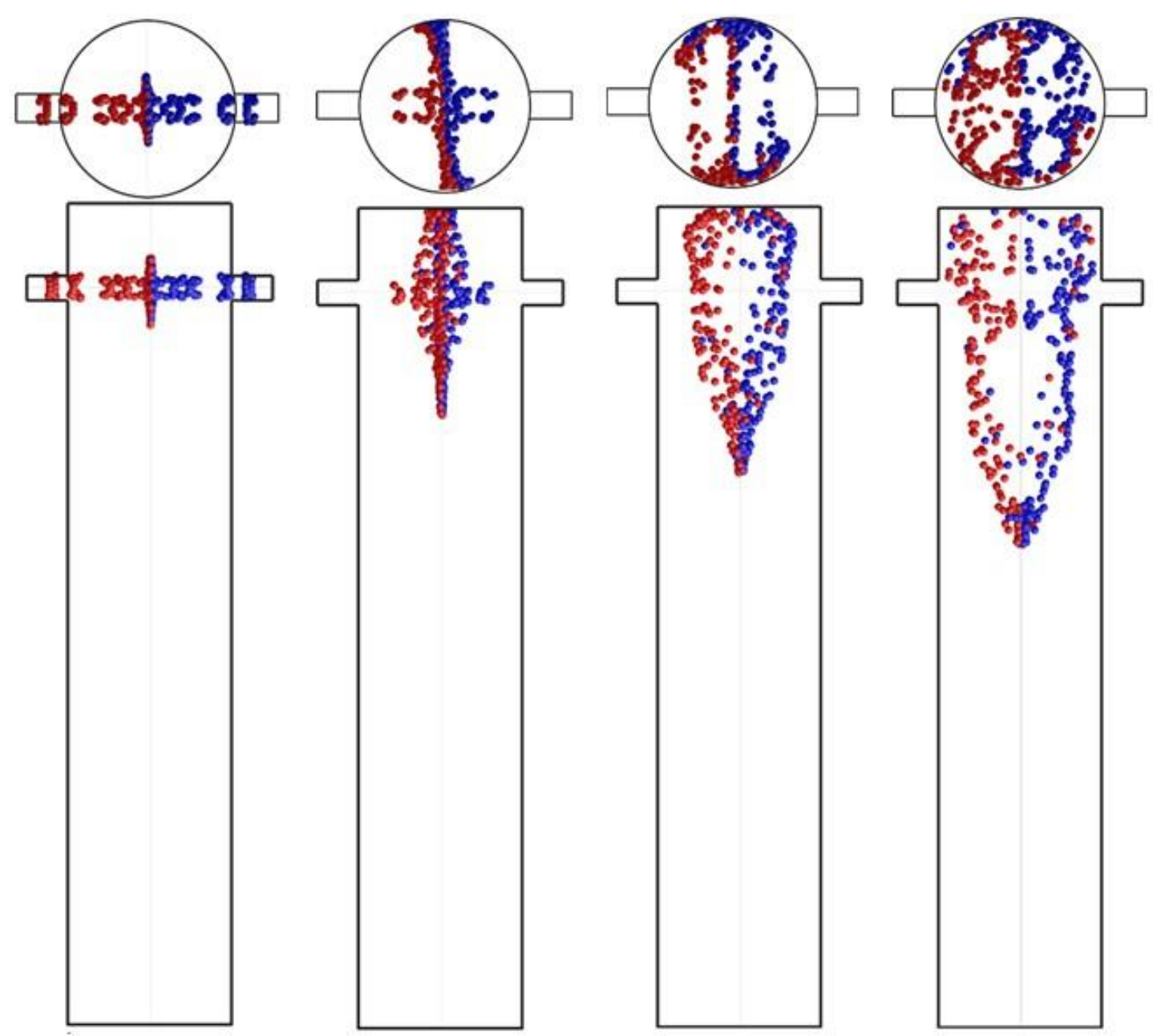

(a)

(b)

(c)

(d)

Figure 12 Top and front views of the particles trajectory for $R e=100$ : a) $t=$ $5.8 \times 10^{-3} \tau$; b) $t=1.7 \times 10^{-2} \tau$; c) $t=3.3 \times 10^{-2} \tau$ and d) $t=6.7 \times 10^{-2} \tau$. 


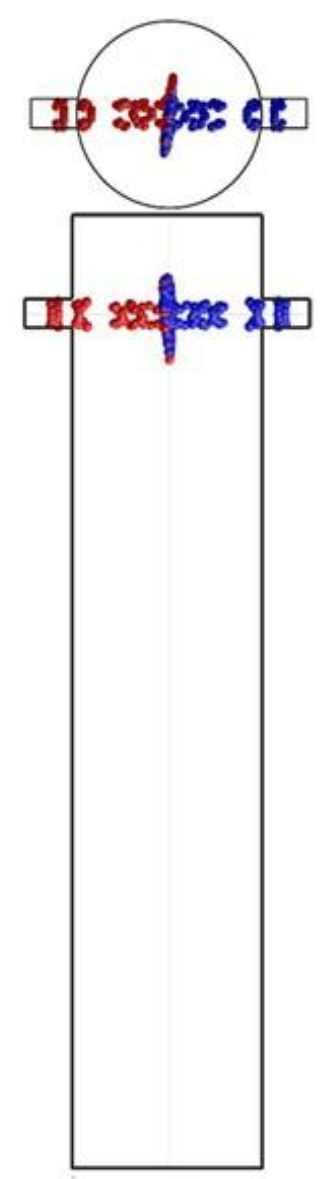

(a)
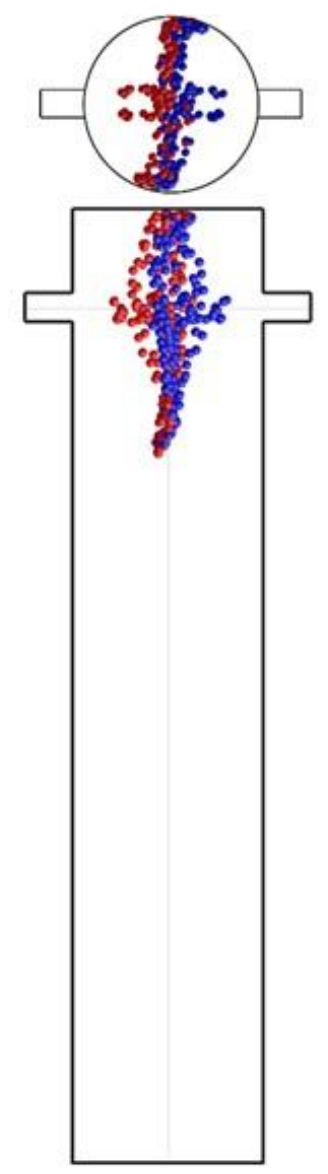

(b)

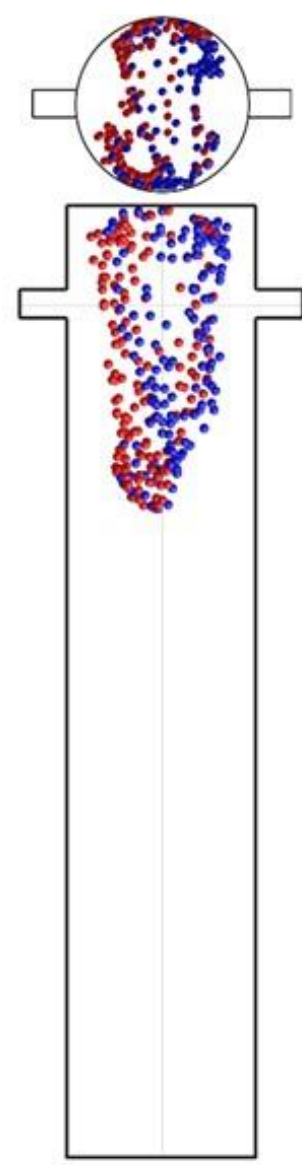

(c)

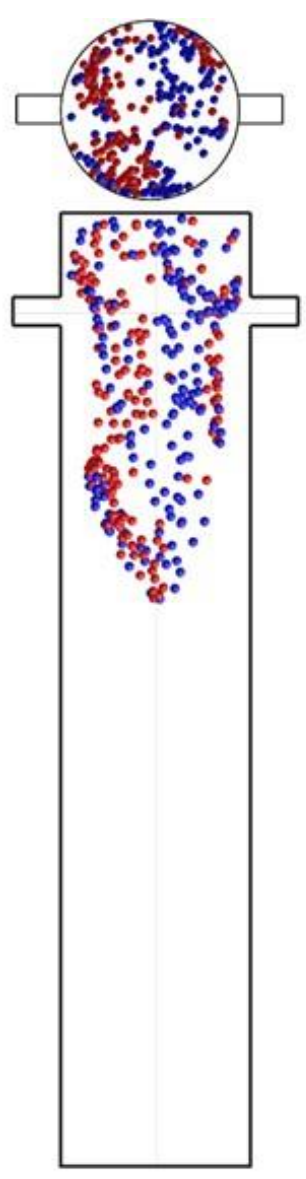

(d)

2

3

Figure 13 Top and front views of the particles trajectory for $R e=110$ : a) $t=$ $5.8 \times 10^{-3} \tau$; b) $t=1.7 \times 10^{-2} \tau$; c) $t=3.3 \times 10^{-2} \tau$ and d) $t=6.7 \times 10^{-2} \tau$. 


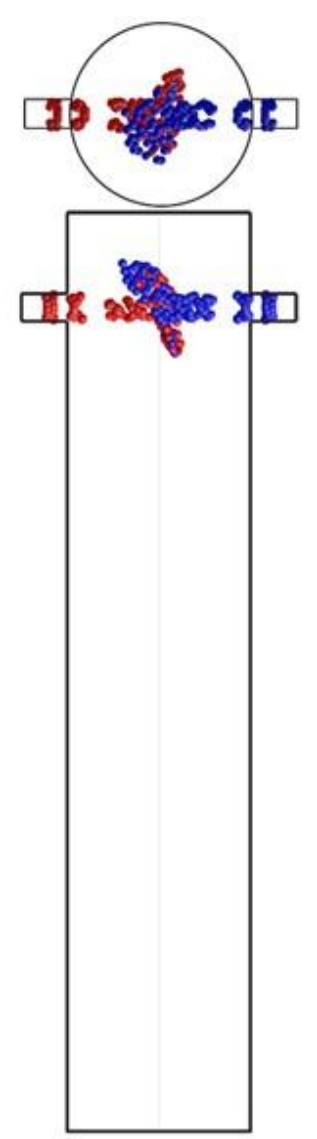

(a)

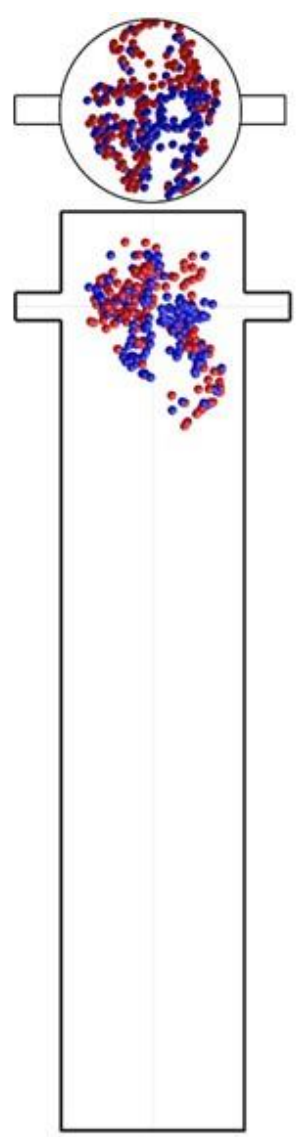

(b)

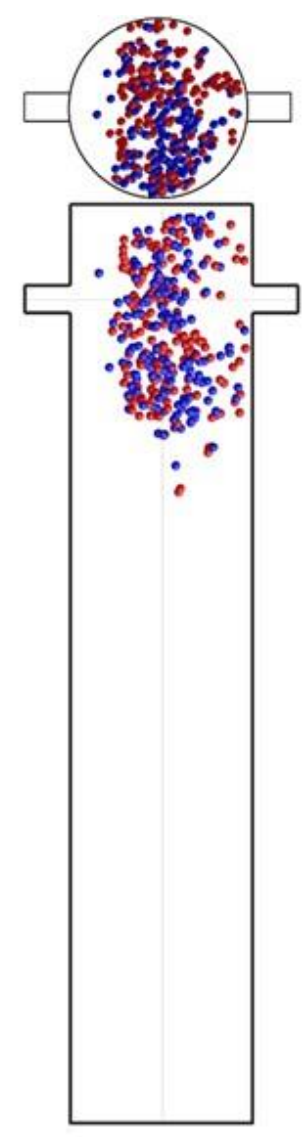

(c)

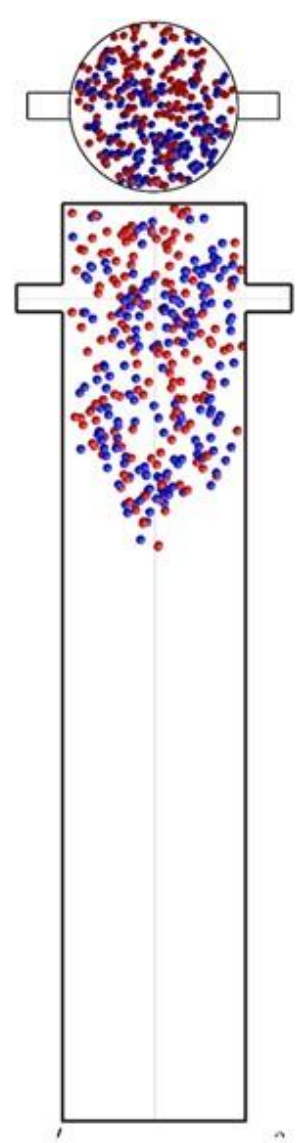

(d)

Figure 14 Top and front views of the particles trajectory for $R e=200$ : a) $t=$ $5.8 \times 10^{-3} \tau$; b) $t=1.7 \times 10^{-2} \tau$; c) $t=3.3 \times 10^{-2} \tau$ and d) $t=6.7 \times 10^{-2} \tau$.

4 


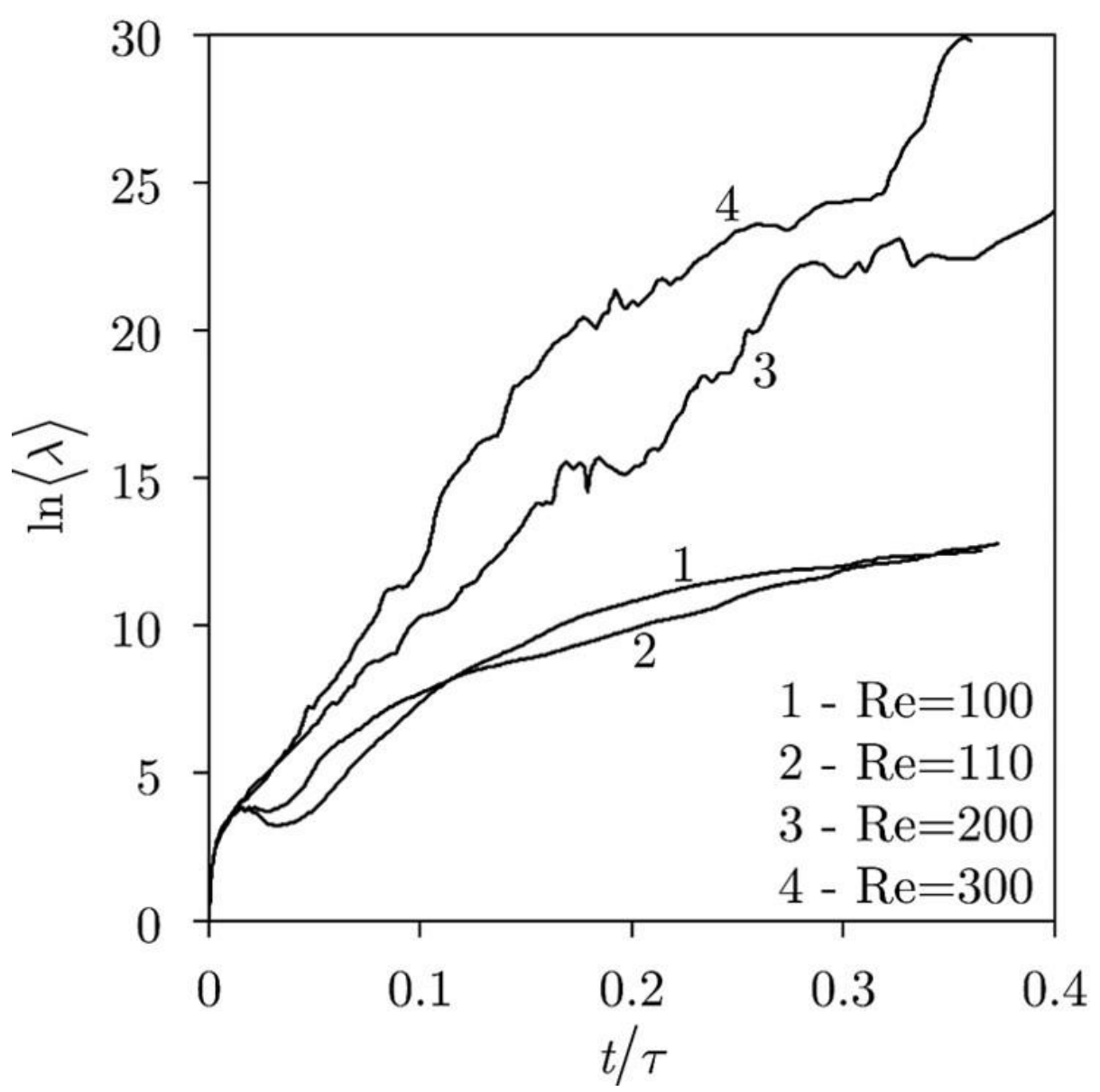

Figure 15 Average particle stretching at several Reynolds Number. 


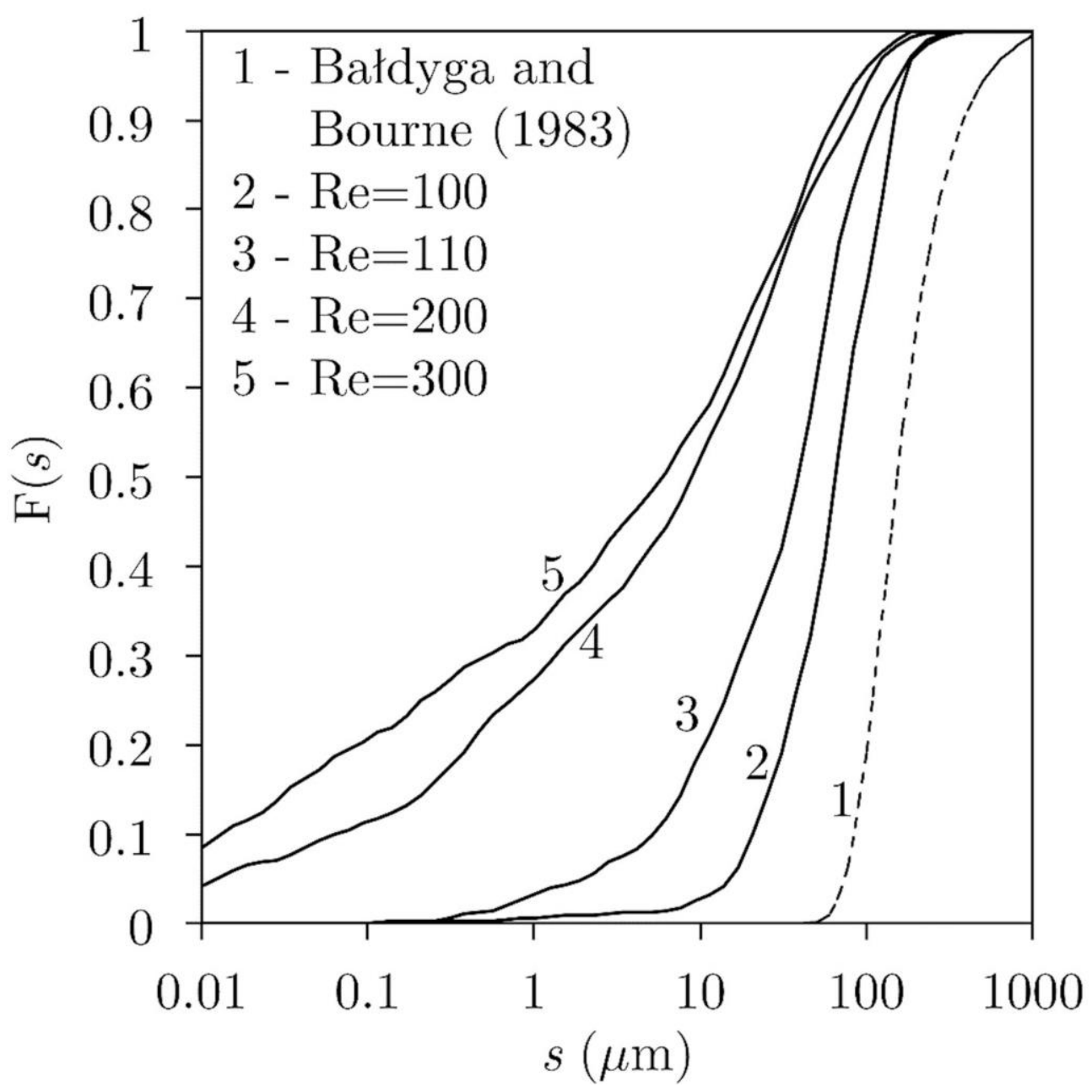

Figure 16 Cumulative striation thickness distribution. 
Table 1 List of experiments with respective feed reactant concentrations, values of $\gamma_{A_{2}}$ and $\gamma_{A_{1}}$ and reaction time (Nunes et al. 2012)

\begin{tabular}{|c|c|c|c|c|}
\hline Experiments & $\begin{array}{l}\text { Reactant concentration in the } \\
\text { feed }\end{array}$ & $\gamma_{\mathrm{A}_{2}}$ & $\gamma_{\mathrm{A}_{1}}$ & $\begin{array}{c}t_{R} \\
\text { (ms) }\end{array}$ \\
\hline Exp \#1 and \#2 & $\begin{array}{l}C_{A_{1}}^{\text {feed }}=1.1 \mathrm{~mol} \mathrm{~m}^{-3} \\
C_{A_{2}}^{\text {feed }}=6.6 \mathrm{~mol} \mathrm{~m}^{-3} \\
C_{\mathrm{B}}^{\text {feed }}=1.0 \mathrm{~mol} \mathrm{~m}^{-3}\end{array}$ & 6 & 1.1 & 21 \\
\hline Exp \#3 & $\begin{array}{l}C_{\mathrm{A}_{1}}^{\mathrm{feed}}=1.1 \mathrm{~mol} \mathrm{~m}^{-3} \\
C_{\mathrm{A}_{2}}^{\mathrm{feed}}=3.3 \mathrm{~mol} \mathrm{~m}^{-3} \\
C_{\mathrm{B}}^{\text {feed }}=1.0 \mathrm{~mol} \mathrm{~m}^{-3}\end{array}$ & 3 & & \\
\hline Exp \#4 & $\begin{array}{l}C_{\mathrm{A}_{1}}^{\mathrm{feed}}=1.1 \mathrm{~mol} \mathrm{~m}^{-3} \\
C_{\mathrm{A}_{2}}^{\text {feed }}=1.1 \mathrm{~mol} \mathrm{~m}^{-3} \\
C_{\mathrm{B}}^{\mathrm{feed}}=1.0 \mathrm{~mol} \mathrm{~m}^{-3}\end{array}$ & 1 & & \\
\hline Exp \#5 & $\begin{array}{l}C_{\mathrm{A}_{1}}^{\mathrm{feed}}=0.24 \mathrm{~mol} \mathrm{~m}^{-3} \\
C_{\mathrm{A}_{2}}^{\text {feed }}=1.44 \mathrm{~mol} \mathrm{~m}^{-3} \\
C_{\mathrm{B}}^{\mathrm{feed}}=0.2 \mathrm{~mol} \mathrm{~m}^{-3}\end{array}$ & 6 & 1.2 & 105 \\
\hline Exp \#6 & $\begin{aligned} C_{\mathrm{A}_{1}}^{\mathrm{feed}} & =0.24 \mathrm{~mol} \mathrm{~m}^{-3} \\
C_{\mathrm{A}_{2}}^{\text {feed }} & =0.72 \mathrm{~mol} \mathrm{~m}^{-3} \\
C_{\mathrm{B}}^{\text {feed }} & =0.2 \mathrm{~mol} \mathrm{~m}^{-3}\end{aligned}$ & 3 & & \\
\hline Exp \#7 & $\begin{aligned} C_{\mathrm{A}_{1}}^{\mathrm{feed}} & =0.24 \mathrm{~mol} \mathrm{~m}^{-3} \\
C_{\mathrm{A}_{2}}^{\text {feed }} & =0.24 \mathrm{~mol} \mathrm{~m}^{-3} \\
C_{\mathrm{B}}^{\mathrm{feed}} & =0.2 \mathrm{~mol} \mathrm{~m}^{-3}\end{aligned}$ & 1 & & \\
\hline
\end{tabular}

Table 2 List of Lamellar Model Parameters

\begin{tabular}{ccc}
$d=s_{0}=1.50 \mathrm{~mm}$ & $\rho=1000 \mathrm{~kg} \mathrm{~m}^{-3}$ & $k_{1}=14 \times 10^{4} \mathrm{~m}^{3} \mathrm{~mol}^{-1} \mathrm{~s}^{-1}$ \\
$D=10 \mathrm{~mm}$ & $n=2$ & $k_{2}=2.56 \mathrm{~m}^{3} \mathrm{~mol}^{-1} \mathrm{~s}^{-1}$ \\
$\mu=20 \mathrm{mPa} . \mathrm{s}$ & $r_{s}=1$ & $k_{3}=95 \mathrm{~m}^{3} \mathrm{~mol}^{-1} \mathrm{~s}^{-1}$ \\
\hline
\end{tabular}


Table 1 List of experiments with respective feed reactant concentrations, values of $\gamma_{A_{2}}$ and $\gamma_{A_{1}}$ and reaction time (Nunes et al. 2012)

\begin{tabular}{|c|c|c|c|c|}
\hline Experiments & $\begin{array}{l}\text { Reactant concentration in the } \\
\text { feed }\end{array}$ & $\gamma_{\mathrm{A}_{2}}$ & $\gamma_{\mathrm{A}_{1}}$ & $\begin{array}{c}t_{R} \\
\text { (ms) }\end{array}$ \\
\hline Exp \#1 and \#2 & $\begin{array}{l}C_{A_{1}}^{\text {feed }}=1.1 \mathrm{~mol} \mathrm{~m}^{-3} \\
C_{A_{2}}^{\text {feed }}=6.6 \mathrm{~mol} \mathrm{~m}^{-3} \\
C_{\mathrm{B}}^{\text {feed }}=1.0 \mathrm{~mol} \mathrm{~m}^{-3}\end{array}$ & 6 & 1.1 & 21 \\
\hline Exp \#3 & $\begin{array}{l}C_{\mathrm{A}_{1}}^{\mathrm{feed}}=1.1 \mathrm{~mol} \mathrm{~m}^{-3} \\
C_{\mathrm{A}_{2}}^{\mathrm{feed}}=3.3 \mathrm{~mol} \mathrm{~m}^{-3} \\
C_{\mathrm{B}}^{\text {feed }}=1.0 \mathrm{~mol} \mathrm{~m}^{-3}\end{array}$ & 3 & & \\
\hline Exp \#4 & $\begin{array}{l}C_{\mathrm{A}_{1}}^{\mathrm{feed}}=1.1 \mathrm{~mol} \mathrm{~m}^{-3} \\
C_{\mathrm{A}_{2}}^{\text {feed }}=1.1 \mathrm{~mol} \mathrm{~m}^{-3} \\
C_{\mathrm{B}}^{\mathrm{feed}}=1.0 \mathrm{~mol} \mathrm{~m}^{-3}\end{array}$ & 1 & & \\
\hline Exp \#5 & $\begin{array}{l}C_{\mathrm{A}_{1}}^{\mathrm{feed}}=0.24 \mathrm{~mol} \mathrm{~m}^{-3} \\
C_{\mathrm{A}_{2}}^{\text {feed }}=1.44 \mathrm{~mol} \mathrm{~m}^{-3} \\
C_{\mathrm{B}}^{\mathrm{feed}}=0.2 \mathrm{~mol} \mathrm{~m}^{-3}\end{array}$ & 6 & 1.2 & 105 \\
\hline Exp \#6 & $\begin{aligned} C_{\mathrm{A}_{1}}^{\mathrm{feed}} & =0.24 \mathrm{~mol} \mathrm{~m}^{-3} \\
C_{\mathrm{A}_{2}}^{\text {feed }} & =0.72 \mathrm{~mol} \mathrm{~m}^{-3} \\
C_{\mathrm{B}}^{\text {feed }} & =0.2 \mathrm{~mol} \mathrm{~m}^{-3}\end{aligned}$ & 3 & & \\
\hline Exp \#7 & $\begin{aligned} C_{\mathrm{A}_{1}}^{\mathrm{feed}} & =0.24 \mathrm{~mol} \mathrm{~m}^{-3} \\
C_{\mathrm{A}_{2}}^{\text {feed }} & =0.24 \mathrm{~mol} \mathrm{~m}^{-3} \\
C_{\mathrm{B}}^{\mathrm{feed}} & =0.2 \mathrm{~mol} \mathrm{~m}^{-3}\end{aligned}$ & 1 & & \\
\hline
\end{tabular}

Table 2 List of Lamellar Model Parameters

\begin{tabular}{ccc}
$d=s_{0}=1.50 \mathrm{~mm}$ & $\rho=1000 \mathrm{~kg} \mathrm{~m}^{-3}$ & $k_{1}=14 \times 10^{4} \mathrm{~m}^{3} \mathrm{~mol}^{-1} \mathrm{~s}^{-1}$ \\
$D=10 \mathrm{~mm}$ & $n=2$ & $k_{2}=2.56 \mathrm{~m}^{3} \mathrm{~mol}^{-1} \mathrm{~s}^{-1}$ \\
$\mu=20 \mathrm{mPa} . \mathrm{s}$ & $r_{s}=1$ & $k_{3}=95 \mathrm{~m}^{3} \mathrm{~mol}^{-1} \mathrm{~s}^{-1}$ \\
\hline
\end{tabular}




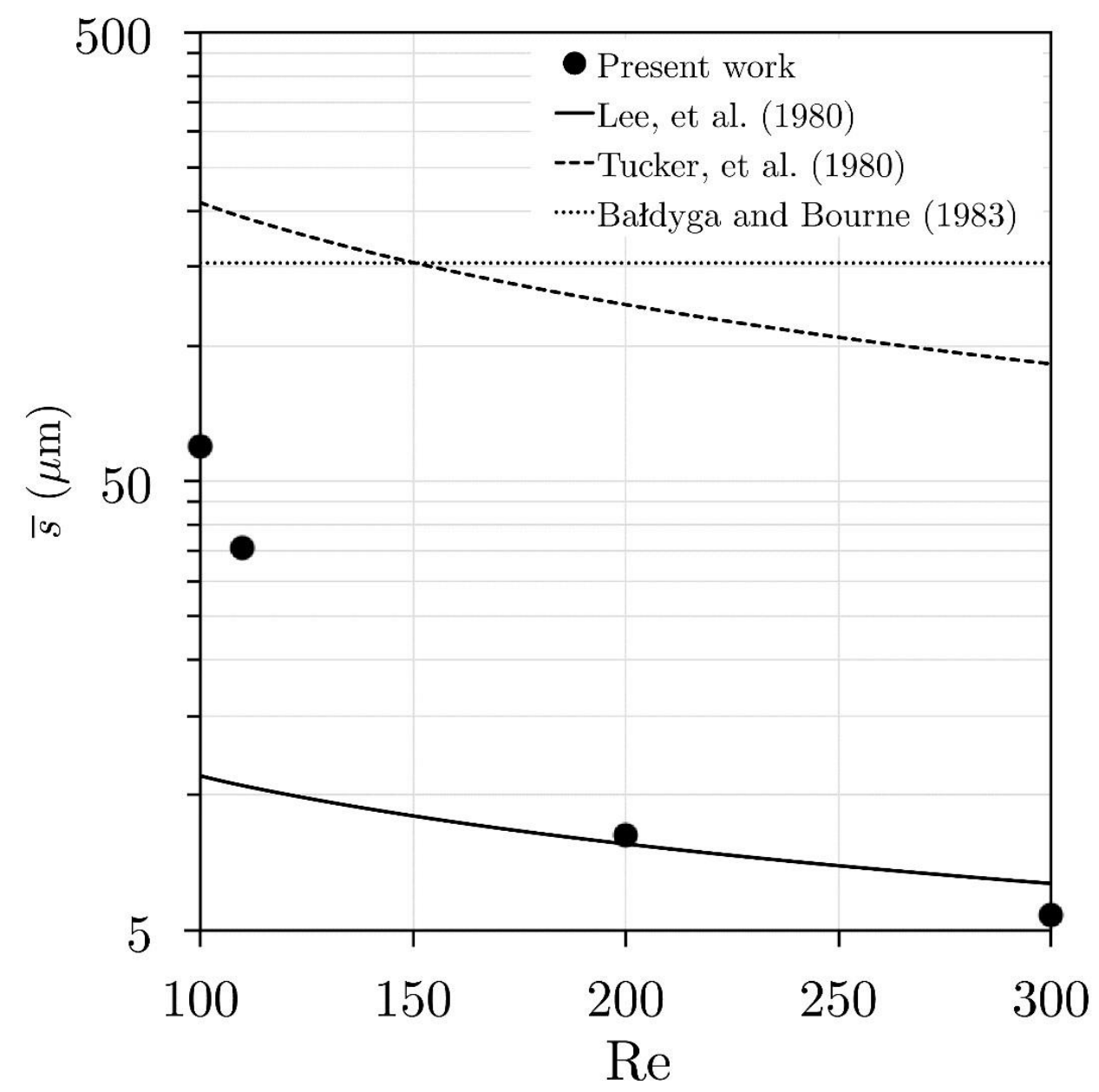

Figure 17 Mean striation thickness as a function of Reynolds Number. 
Table 1 List of experiments with respective feed reactant concentrations, values of $\gamma_{A_{2}}$ and $\gamma_{A_{1}}$ and reaction time (Nunes et al. 2012)

\begin{tabular}{|c|c|c|c|c|}
\hline Experiments & $\begin{array}{l}\text { Reactant concentration in the } \\
\text { feed }\end{array}$ & $\gamma_{\mathrm{A}_{2}}$ & $\gamma_{\mathrm{A}_{1}}$ & $\begin{array}{c}t_{R} \\
\text { (ms) }\end{array}$ \\
\hline Exp \#1 and \#2 & $\begin{array}{l}C_{A_{1}}^{\text {feed }}=1.1 \mathrm{~mol} \mathrm{~m}^{-3} \\
C_{A_{2}}^{\text {feed }}=6.6 \mathrm{~mol} \mathrm{~m}^{-3} \\
C_{\mathrm{B}}^{\text {feed }}=1.0 \mathrm{~mol} \mathrm{~m}^{-3}\end{array}$ & 6 & 1.1 & 21 \\
\hline Exp \#3 & $\begin{array}{l}C_{\mathrm{A}_{1}}^{\mathrm{feed}}=1.1 \mathrm{~mol} \mathrm{~m}^{-3} \\
C_{\mathrm{A}_{2}}^{\mathrm{feed}}=3.3 \mathrm{~mol} \mathrm{~m}^{-3} \\
C_{\mathrm{B}}^{\text {feed }}=1.0 \mathrm{~mol} \mathrm{~m}^{-3}\end{array}$ & 3 & & \\
\hline Exp \#4 & $\begin{array}{l}C_{\mathrm{A}_{1}}^{\mathrm{feed}}=1.1 \mathrm{~mol} \mathrm{~m}^{-3} \\
C_{\mathrm{A}_{2}}^{\text {feed }}=1.1 \mathrm{~mol} \mathrm{~m}^{-3} \\
C_{\mathrm{B}}^{\mathrm{feed}}=1.0 \mathrm{~mol} \mathrm{~m}^{-3}\end{array}$ & 1 & & \\
\hline Exp \#5 & $\begin{array}{l}C_{\mathrm{A}_{1}}^{\mathrm{feed}}=0.24 \mathrm{~mol} \mathrm{~m}^{-3} \\
C_{\mathrm{A}_{2}}^{\text {feed }}=1.44 \mathrm{~mol} \mathrm{~m}^{-3} \\
C_{\mathrm{B}}^{\mathrm{feed}}=0.2 \mathrm{~mol} \mathrm{~m}^{-3}\end{array}$ & 6 & 1.2 & 105 \\
\hline Exp \#6 & $\begin{aligned} C_{\mathrm{A}_{1}}^{\mathrm{feed}} & =0.24 \mathrm{~mol} \mathrm{~m}^{-3} \\
C_{\mathrm{A}_{2}}^{\text {feed }} & =0.72 \mathrm{~mol} \mathrm{~m}^{-3} \\
C_{\mathrm{B}}^{\text {feed }} & =0.2 \mathrm{~mol} \mathrm{~m}^{-3}\end{aligned}$ & 3 & & \\
\hline Exp \#7 & $\begin{aligned} C_{\mathrm{A}_{1}}^{\mathrm{feed}} & =0.24 \mathrm{~mol} \mathrm{~m}^{-3} \\
C_{\mathrm{A}_{2}}^{\text {feed }} & =0.24 \mathrm{~mol} \mathrm{~m}^{-3} \\
C_{\mathrm{B}}^{\mathrm{feed}} & =0.2 \mathrm{~mol} \mathrm{~m}^{-3}\end{aligned}$ & 1 & & \\
\hline
\end{tabular}

Table 2 List of Lamellar Model Parameters

\begin{tabular}{ccc}
$d=s_{0}=1.50 \mathrm{~mm}$ & $\rho=1000 \mathrm{~kg} \mathrm{~m}^{-3}$ & $k_{1}=14 \times 10^{4} \mathrm{~m}^{3} \mathrm{~mol}^{-1} \mathrm{~s}^{-1}$ \\
$D=10 \mathrm{~mm}$ & $n=2$ & $k_{2}=2.56 \mathrm{~m}^{3} \mathrm{~mol}^{-1} \mathrm{~s}^{-1}$ \\
$\mu=20 \mathrm{mPa} . \mathrm{s}$ & $r_{s}=1$ & $k_{3}=95 \mathrm{~m}^{3} \mathrm{~mol}^{-1} \mathrm{~s}^{-1}$ \\
\hline
\end{tabular}

